\title{
Chapter 20 \\ Nanofibers for Water and Wastewater Treatment: Recent Advances and Developments
}

\section{Leonard D. Tijing, Minwei Yao, Jiawei Ren, Chan-Hee Park, Cheol Sang Kim and Ho Kyong Shon}

\begin{abstract}
Materials of nanofibrous morphology and structure are attractive for solving environmental problems including water-related issues. In recent years, increasing interest is geared on the use of specially designed electrospun nanofibers for water/wastewater treatment applications. The nanofibers can be used in the form of nonwoven structures, as stand-alone membranes, as support layer or as a surface modification layer that enables added functionality to a composite material. Continuous research has been carried out in optimizing the nanofiber membrane design and structure by manipulating material, process and surrounding parameters in the electrospinning process. This chapter highlights the recent advances and developments on the potential and application of electrospun nanofibers for water/ wastewater treatment. Comprehensive discussion is presented here on various designs and structures of nanofibers and their applications to water-related treatment and the future prospects of such materials.
\end{abstract}

Keywords Nanofiber $\cdot$ Membrane $\cdot$ Electrospinning $\cdot$ Desalination Water/wastewater treatment

\subsection{Introduction}

Electrospun nanofibers have gained wide interest and attention in recent years (Chronakis 2005; Jiang et al. 2018; Xue et al. 2017). The nanofibers boast attractive properties such as very high surface area, controllable pore sizes, high porosity,

L. D. Tijing $(\bowtie) \cdot$ M. Yao $\cdot$ J. Ren $\cdot$ H. K. Shon

Faculty of Engineering and Information Technology, School of Civil and Environmental Engineering, Centre for Technology in Water and Wastewater, University of Technology Sydney, 15 Broadway, Sydney 2007, NSW, Australia e-mail: leonard.tijing@uts.edu.au

C.-H. Park · C. S. Kim

Division of Mechanical Design Engineering, Chonbuk National University, Jeonju, Jeonbuk 561-756, Republic of Korea

(C) Springer Nature Singapore Pte Ltd. 2019

X.-T. Bui et al. (eds.), Water \& Wastewater Treatment Technologies, https://doi.org/10.1007/XXX_20 
interconnected pore structure, and adequate mechanical strength that are desirable for many different applications (e.g., biomedical, energy harvesting, clothing, smart materials, sensors, water and wastewater treatment, etc.) (Tijing et al. 2017). The ease of fabrication and functionalization makes it more promising. The nanofibers have also attracted many research activities on their preparation, modification, and treatment capabilities for water and wastewater treatment processes. This is primarily attributed to the filter-like characteristics of nanofiber mats, which are similar to the filters used in the water/wastewater treatment field. Nanofibers as membranes take a center role in this review as most nanofibers reported in literature are prepared in this structure/form. However, nanofibers have also been used as electrodes or adsorbent materials for other processes.

Membrane technology plays a significant role in ensuring water security around the world (Shannon et al. 2008). This is because of its high efficiency, cost-effectiveness, and high performance in treating different types of water sources towards the desired water quality. Among the most common membrane separation processes include reverse osmosis, microfiltration, ultrafiltration, and nanofiltration. Polymeric membranes are the most widely available in the market but still face a number of challenges in terms of fouling, degradation, and their overall stability (Le and Nunes 2016). Hence, there is a surge of research done on improving the polymeric membrane performance by manipulating their design, structure, and physiochemical properties. Most commonly, these membranes are in the form of flat sheet and hollow fiber structures. In recent years, the use of nanotechnology and nanomaterials has considerably improved the development of membranes and especially on the use of electrospun nanofibers (Goh et al. 2016).

In the past two decades, research on nanofibers as materials for water and wastewater treatment (membranes, electrodes, adsorbents, etc.) has surged dramatically with many works done on the nanofiber synthesis, surface modification, nanomaterial incorporation, mechanical and thermal stability improvement, etc. This chapter reviews the recent adyances on the developments of nanofibers and their application to water and wastewater treatment.

\subsection{Electrospun Nanofibers: Fabrication, Design, and Properties}

\subsubsection{Introduction to Electrospinning and Nanofibers}

Nanofibers loosely refer to fibers having diameters less than $1 \mu \mathrm{m}$, and have been gaining wide interests in many applications due to their exciting properties and functionalities (Bhardwaj and Kundu 2010). There are a number of ways to fabricate nanofibers such as template synthesis, melt blowing, self-assembly, nanolithography, and electrospinning. For membrane fabrication especially, electrospinning is the most facile and effective way of producing nanofiber 
membranes especially with the use of polymeric solutions (Huang et al. 2003; Ahmed et al. 2015). The recent advances on upscaling and mass production capability of electrospinning have greatly increased its potential use and promise for future development of functional materials and membranes (Luana et al. 2013).

Simply, electrospinning uses a high-voltage electric field to force a polymer solution to jet out from a small nozzle opening and elongate while whipping instantaneously towards a grounded collector where it is collected and form a nonwoven flat sheet membrane structure. Figure 20.1 shows a schematic of the electrospinning system. The process itself is simple, yet the optimization of the different parameters such as the material, process, and posttreatment parameters can be challenging, when designing a specific structure and property of the nanofiber membrane. The most common material used for electrospinning is polymer-based materials, with more than 200 of such polymers have been made into different nanofiber structures. Several papers have summarized the various strategies in nanofiber membrane fabrication and modification in recent years including the effect of process/operating parameters, material selection and preparation, and posttreatment conditions (Ahmed et al. 2015; Teo and Ramakrishna 2006; Tijing et al. 2014a). Nanofiber membranes can be divided into three main designs: (1) neat nanofiber membranes, (2) composite nanofiber membranes, and (3) surfacemodified/functionalized nanofiber membranes.

The use of nanofiber membranes for water and wastewater treatment applications has attracted wide interest in the last 20 years. This is primarily because of the versatility of the nanofiber formation, where the porosity, pore size, structure, surface properties, and mechanical and thermal stability can be controlled

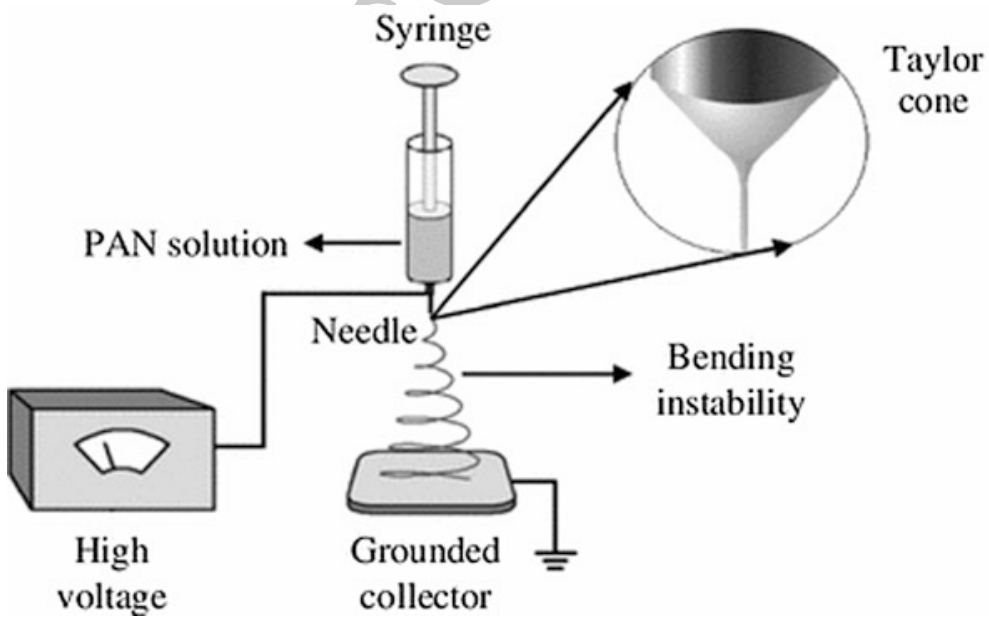

Fig. 20.1 Schematic of electrospinning system showing the three main components: high voltage power supply, syringe containing polymer solution, and grounded collector. The enlarged inset figure also shows the Taylor cone formation when jet overcomes the surface tension of solution to emit fibers. Adapted from Zhang et al. (2014) 
(Tijing et al. 2016). Depending on the desired properties, nanofiber membranes can be made into hydrophilic, hydrophobic, omniphobic, highly porous, as support material, as self-standing membrane, as antibacterial or antifoulling membrane, as self-heating membrane, as adsorbent, and many other properties. This chapter reveals the attractive properties and applications of such nanofiber membranes mainly for water and wastewater treatment processes.

\subsubsection{Electrospinning Parameters}

Electrospinning is a facile technique in producing nonwoven nanofibers mats or membranes. Though the concept and method are quite simple, producing nanofibers with the desired properties and design could be tricky (Tijing et al. 2014a). The material selection and preparation are essential parameters for the resulting nanofibers. The polymer concentration of the solution has a strong effect on the fiber size, the presence of beads, and the electrospinnability of the solution. Conflicting studies have been reported in the literature about the effect of polymer concentration on fiber size, but majority of the reports indicated that high polymer concentration results in bigger fibers, while low polymer concentration produces smaller fibers (Ki et al. 2005). In addition, below a certain threshold polymer concentration (which varies depending on the type of polymer used), there will be higher tendency for sputtering which results in the production of beads-on-string fiber formation. Beads on nanofibers are usually regarded as defects as they can serve as stress points for any external load towards the nanofiber, which consequently affects its overall mechanical properties. However, in some studies, the beads could be a desired design, which adds more roughness and increases surface hydrophobicity (Tijing et al. 2016). The polymer concentration is closely related to the solution viscosity. At higher polymer concentration, solution viscosity in most cases also increases. Thus, it was observed that higher concentration (therefore more viscous) has more chances of clogging in the electrospinning nozzle and eventually block it. Thus, fiber formation is inhibited. Nevertheless, the less viscous solution is also not desired because it could lead to sputtering effect. So that a certain viscosity for a specific polymer solution is required for smooth fiber formation. Another solution parameter that is very much related with concentration and viscosity is the polymer molecular weight. Generally, there is a minimum molecular weight for a specific polymer for it to have good electrospinnability (Tao and Shivkumar 2007; Haghi and Akbari 2007). Hence, the importance of optimizing the solution parameters is essential to fabricate smooth, cylindrical, and uniform nanofiber mat.

For jet formation to proceed, the solution must be conductive enough to improve its charge carrying capability so that the applied electric field can promote the repulsion of charges in the jet that stretches and elongates the polymer until it is collected (Talwar et al. 2010). Polymers innately have charges themselves, thus nanofiber formation is possible. However, the kind of solvent and additives used greatly enhances the conductivity of the solution which also helps in the 
electrospinnablity of the solution (Kim et al. 2005). Studies have shown that adding salts in the polymer solution increases conductivity thereby increasing the chances of further elongation resulting in thinner fibers. The presence of additives also promotes the formation of nanonets due to charge attraction from neighboring particles (Barakat et al. 2009).

In as much as the material selection and preparation are important factors, the process conditions also dictate much of the resulting nanofiber design and properties. The applied electric field is a requirement for nanofiber formation. This is basically dictated by the applied voltage (Sill and von Recum 2008) and the nozzle tip-to-collector distance (TCD). At high applied voltage, the driving force that helps overcome the surface tension of the solution to emit thin fibers is much greater, hence expecting more charge repulsion resulting in thinner nanofiber formation. However, one must be careful not to increase too much of the voltage as this could also lead to sputtering as the driving force is too high that there is sudden breakage of polymer entanglement at the nozzle tip leading to sputtering. Depending on the polymer used, the applied voltage is usually in the range of $5-40 \mathrm{kV}$. There is always a threshold voltage for specific kind of material and its solution properties.

As mentioned above, the tip-to-collector distance is also important. At a longer $\mathrm{TCD}$, once the polymer solution is emitted from the nozzle, the longer flight time towards the collector gives higher chance for the solvent to evaporate, thus leading to thinner nanofiber formation (Matabola and Moutloali 2013). On the other hand, too short of TCD would likely result in film formation instead of fibers, as the short flight time is not enough for the solvent to evaporate in air. For most electrospinning setup, optimizing the TCD together with other parameters is essential. Usually, a TCD between 15 and $25 \mathrm{~cm}$ is used in many studies. As nanofibers are emitted from the nozzle via applied electric field as driving force, the amount of solution that actually is exposed to the nozzle tip is controlled by the solution feed rate. In most cases, a syringe pump is used to push the solution, and the feed rate is usually $1 \mathrm{ml} / \mathrm{h}$ or lower. This is to ensure that there is sufficient amount of solution going to the nozzle, ideally in the same rate of the fiber emission from the nozzle (Matabola and Moutloali 2013). If the solution feed rate is too slow, this usually leads to uneven and nonuniform fiber formation as not enough solution is being emitted. On the other hand, too fast feed rate also leads to beaded fibers as the supply of solution at the nozzle tip is over accumulated. This produces beaded structures, garland, or even ribbon-like fiber formation, as observed by other studies. Hence, it is necessary that a suitable feed rate is used for electrospinning.

Other factors to consider for electrospinning of nanofibers are its ambient condition-especially temperature and relative humidity, and the way it is processed post-fabrication. The surrounding humidity during electrospinning is found to have an important effect on the nanofiber morphology and structure (De Vrieze et al. 2008). At low humidity, i.e., less moisture in air, there is bigger tendency for rapid evaporation of solvents to the air as the air has higher capacity to hold moisture. This usually results in thinner nanofiber formation. On the other hand, high humidity can produce pores on the nanofiber as the moisture in the air can condense on the formed nanofiber. However, if the polymer used is water soluble, high 
Table 20.1 Effect of electrospinning parameters on the nanofiber structure and morphology

\begin{tabular}{l|l}
\hline $\begin{array}{l}\text { Electrospinning } \\
\text { parameter }\end{array}$ & Effect \\
\hline Applied voltage & High voltage generally leads to thinner fibers \\
\hline Feed flow rate & $\begin{array}{l}\text { Most flow rates are limited to } 1 \mathrm{ml} / \mathrm{h} \text { or lower to enable good fiber } \\
\text { formation }\end{array}$ \\
\hline $\begin{array}{l}\text { Tip-to-collector distance } \\
\text { (TCD) }\end{array}$ & $\begin{array}{l}\text { Longer TCD results to thinner fibers } \\
\text { Very near TCD may produce thin film structure instead of } \\
\text { nanofibers }\end{array}$ \\
\hline Solution concentration & $\begin{array}{l}\text { High concentration may clog the nozzle } \\
\text { Low concentration may lead to sputtering }\end{array}$ \\
\hline Solution conductivity & High conductivity leads to thinner fibers \\
\hline $\begin{array}{l}\text { Ambient humidity and } \\
\text { temperature }\end{array}$ & $\begin{array}{l}\text { Higher humidity leads to pore formation on nanofibers unless if the } \\
\text { polymer is water soluble, which leads to thinner nanofiber }\end{array}$ \\
\hline Hot-press posttreatment & $\begin{array}{l}\text { Increases the mechanical strength of nanofibers mat } \\
\text { Reduces pore sizes if there is fusion of fiber nodes }\end{array}$ \\
\hline
\end{tabular}

humidity could potentially produce thinner fibers as the moisture in the air helps in further dis solution of the fiber while it is on flight to the collector. The temperature of the environment also has similar effect. Higher temperature (which also could mean drier surrounding) could lead to less viscous solution hence promoting thinner fibers. The post-fabrication treatment methods help in improving the overall mechanical, and morphological properties of the nanofiber membranes. Hot-press treatment in particular, which presses the nanofiber between two hot plates or just exposed to high temperature in an oven, promotes controlled melting of some nanofiber nodes that leads to node fusion thereby increasing the overall mechanical properties. However, this method also reduces the overall pore size and porosity due to the fusion occurrence (De Vrieze et al. 2008). Table 20.1 summarizes the effect of various electrospinning parameters on the nanofiber formation, structure, and morphology.

As a guide, smooth nanofiber formation with uniform fiber sizes is always the ideal structure desired for nanofibers. This can be controlled by manipulating various parameters before, during, and after electrospinning process. The proper optimization of these many parameters for any specific polymer used is necessary to achieve the desired nanofiber morphology and properties.

\subsubsection{Electrospun Nanofiber Design and Properties}

The versatility of electrospinning to produce nanofibers is one of its most attractive features for many applications. Nanofibers can be designed and prepared in many configurations, structures, and functionalities in a more facile way compared to other material preparation processes. In its basic form, nanofibers are in nonwoven 
form that resembles a flat sheet mat or membrane. The pore size and porosity are in the range of $0.5-10 \mu \mathrm{m}$, and $>70 \%$, respectively. The pore size distribution is usually a little wide unless posttreatment processes are done to the nanofiber mat. The nanofibers are formed in an overlapping manner, hence the overall structure is full of voids and less torturous. There is an interconnection of the pores from the surface down to the bottom of the mat. Thus, this kind of structure found its application in water treatment application as filtration membrane. As nanofibers are overlapping, they form surface nano-micro roughness that affects the wettability of the material. If a hydrophobic polymer is used for electrospinning, the resulting nanofiber mat has more pronounced hydrophobicity due to the added roughness. In a similar way, when hydrophilic polymer is used, it becomes more hydrophilic. For most cases, neat or as-spun nanofibers lack some of the desired surface properties for specific applications. Hence, many works have been done on fabricating nanocomposite mats or membranes (Huang et al. 2003; Tijing et al. 2012a, 2014a). Figure 20.2 shows various nanofiber structures and designs that can be fabricated by electrospinning.

Nanocomposite mats or membranes based on nanofibers can be manufactured via direct blending of component materials (usually nanoparticles or nanofillers mixed with polymer solution), by in situ growth of nanoparticles, or by the posttreatment decoration of nanomaterials. The direct blending method can change the morphology of the nanofibers as the filler element changes the rheological properties of the solution, and at the same time adds new functionalities to the resulting
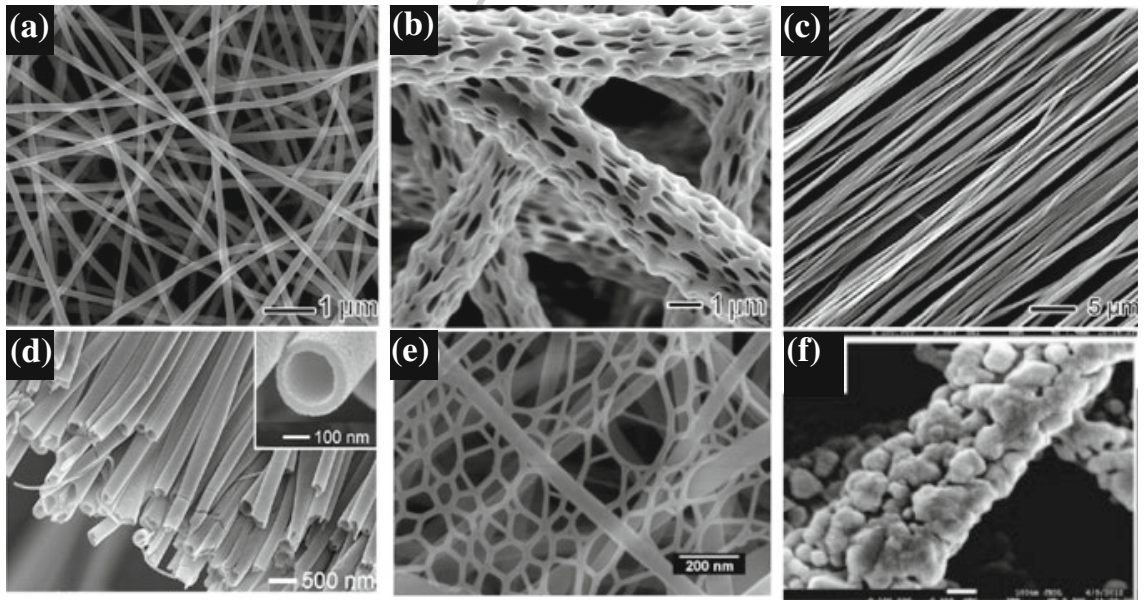

Fig. 20.2 Different nanofiber structures and morphologies that can be fabricated using electrospinning by manipulating electrospinning parameters, nozzle design and collector configuration: a conventional randomly oriented nanofibers (reprinted with permission from Xue et al. 2017), b internally porous nanofibers (Jingwei et al. 2008), c aligned nanofibers (reprinted with permission from $\mathrm{Li}$ et al. 2003), d hollow nanofibers (reprinted with permission from $\mathrm{Li}$ and Xia 2004), e nanonet formation within spaces between nanofibers (Wang et al. 2011), f Ag nanoparticle with hydrophobic coating, surface-modified nanofiber (Liao et al. 2013) 
nanocomposite. This strategy has been investigated in many research studies with inorganic nanoparticles as nanofillers such as $\mathrm{TiO}_{2}, \mathrm{SiO}_{2}$, carbon nanotubes, graphene, $\mathrm{Ag}, \mathrm{Au}$, etc. The inherent properties of these nanofillers provide new functionalities to the nanofibers especially when located on the nanofiber surface. The main challenge for this method is the proper dispersion of these nanoparticles in the polymer solution. To address this dispersion challenge, other researchers impart functionality to the nanofibers by in situ growth of nanoparticles in/on the nanofibers. For example, $\mathrm{AgNO}_{3}$ as a precursor to $\mathrm{Ag}$ nanoparticles has been blended in the polymer solution in liquid form, and then after electrospinning, the mat is exposed to UV light to promote the growth of Ag nanoparticles (Tijing et al. 2012b). This gives Ag more bonding with the polymer matrix thereby lowering the chances of release. However, both of the mentioned approaches (blending or in situ decoration) can oftentimes lead to nanoparticles being embedded inside the polymer matrix, which may enhance the overall mechanical properties, but the added functionality of the nanoparticles may not be as effective as they are not directly exposed on the surface. With this in mind, several groups attempted to functionalize nanofibers by surface modification techniques. This involves adding some functional groups on the nanofiber surface via dipping, spraying, layer-by-layer deposition, and other methods as anchors for the succeeding immobilization of nanoparticles (Liao et al. 2013; Formo et al. 2008). This method ensures that nanoparticles are located on the surface of the nanofibers, rather than inside the polymer matrix. Many of the results showed interesting properties such as added omniphobicity, hydrophibicity, hydrophilicity, antibacterial, self-heating, and other desirable functional qualities. The main drawback of this technique though is the need for really strong bonding of the nanoparticle on the surface, otherwise, they will be easily released and can act as secondary pollutant.

Another way of ensuring that nanoparticles are attached on the surface is via the use of coaxial electrospinning technique (Ma et al. 2012). Here, instead of using only a single nozzle, two concentric nozzles are used wherein the inner nozzle (core) is used as the main polymer carrier or host, while the outer nozzle (shell) is provided with functional materials designed to be attached on the surface of the nanofibers. By simultaneously electrospinning these two solutions, one-step nanoparticle-decorated nano-micro fibers can be made. Though this is very promising, there is difficulty in ensuring proper encapsulation of the core nanofibers with shell nanofibers as the two solutions may differ in properties which behave differently at specified applied voltage. Not only is this technique used for nanoparticle decoration, it can also be utilized to make core-shell structure of two different polymers if the design of such is necessary.

In nanofiber electrospinning, the fiber size is in the range of 100-1000 nm, thus the fibers are not really in the true nano range. A new design in the electrospinning research is towards the formation of true nanofibers or commonly called as nanonets, with a fiber diameter range of 50-80 $\mathrm{nm}$. The nanonets are also known as spider web or spider net form. These nanonets are formed via phase separation splitting due to exposure to high electric field (Lian et al. 2013). Nevertheless, this design can be controlled in its formation, providing much higher surface-area-to-volume ratio if all 
of the nanofiber mat is covered. However, there is difficulty in the full coverage of nanonets of the macrosize of the nanofiber mat. This is an area of great interest for future nanofiber-related work. If one is able to fully capitalize on the nanonet formation, this could provide more reactive sites, and increased porosity overall that might be interesting for filtration applications.

Nanofibers are formed normally in 2D structure, wherein the thickness is very thin while width or length is quite large. However, making a 3D nanofiber structure is very possible and is potentially useful as sorbent materials (Kim and Kim 2007; $\mathrm{Wu}$ et al. 2014). One approach to do doing this is through long-time electrospinning at the same area. As electrospinning progresses, the thickness of the nanofibers increases towards 3D structure. Another way is to electrospin several layers of nanofibers, and just stacking them together to make the 3D structure. The main drawback of this is the robustness of such 3D mats as the individual stacked layer may not adhere well with each other. However, recent studies carried a more interesting approaching, by exposing the 2D nanofiber to chemical gas foaming (Jiang et al. 2015), which expands the nanofiber matrix and produce low-density sponge-like material.

New advances in nanofiber design are geared on producing intraporous structure, i.e., having internal pores within each nanofiber. This can be selectively removing a component from the formed fiber or by inducing polymer-solvent phase separation. The provision of internal porous drastically increases the overall surface area of the nanofibers. Other new works are also on the fabrication of aligned nanofibers $(\mathrm{Wu}$ and Qin 2013), instead of nonwoven form. These aligned nanofibers can be used as electrode or for tissue engineering application. Alignment of nanofibers is done by using a rotating drum at high speed, or by manipulating the collector design (Kim and Kim 2018; Kim et al. 2016). Another interesting structure is the hollow nanofiber design, wherein the core part of the fiber is hollow (Li et al. 2005). This type of design is best achieved using a coaxial or triaxial nozzle, whereby the core layer is selectively dissolved by heat treatment or by some other methods.

Overall, nanofibers present very promising potential for a variety of applications especially in water and wastewater treatment. Membranes are now widely used in many of these water/wastewater treatment applications, and the overall characteristics and properties (high specific surface area, high porosity, controllable pore sizes, interpenetrated pore/structure, adequate mechanical strength, easily functionalized or surface-modified, etc.) of nanofiber-based membranes are highly desirable for filtration applications. Depending on the process application, the nanofibers can be made into hydrophilic or hydrophobic structure, and can be utilized as a stand-alone membrane, as a support layer, or a host polymer/carrier. The nanofiber structure can also be interesting as an electrode material or as sorbent material. The versatility of electrospun nanofibers makes them one of the most researched materials in the last two decades. Still, more research is needed to fully utilize these nanofibers towards commercial use in water/wastewater treatment. 


\subsection{Application of Nanofibers in Desalination, Water and Wastewater Treatment}

\subsubsection{Nanofibers for Desalination and Water Treatment}

Nanofibers as Membranes for Membrane Distillation (MD). MD is a hybrid thermal/membrane separation process that works via phase change, and thus a temperature difference is needed between the feed and cold sides (Tijing et al. 2014b). It is one of the emerging technologies that can utilize low-grade heat as an energy source. In usual cases, the feed side is at higher temperature normally around $40-80{ }^{\circ} \mathrm{C}$ and the cold side is maintained around room temperature $\left(\sim 20{ }^{\circ} \mathrm{C}\right)$ (Tijing et al. 2015). With the use of a hydrophobic membrane, the partial vapor pressure difference between the two fluids enables evaporation of the feed side, only allowing water vapor to pass through the membrane and condensed to water in the cold side. Membranes for MD require hydrophobic surface, high porosity, adequate pore sizes with uniform pore size distribution, high liquid entry pressure, and adequate mechanical strength (Yao et al. 2017). All of these properties can be designed via nanofiber membrane structure using the electrospinning technique. Hence, in the last 10 years, studies using nanofiber membranes for MD have seen exponential surge due to their interesting and desirable properties. The membrane properties and structure play a very important role in the process. Studies using nanofiber membrane exhibited high water flux while maintaining high salt rejection. In comparison, the usual membrane used for MD tests is commercial PVDF or PTFE flat sheet membranes, which perform at relatively lower flux and have wetting issues. Our previous review article on the use of nanofibers for MD presents the promising potentialities of nanofiber membranes (Tijing et al. 2014a). Recent studies have focused on membrane development and modification especially on the design of nanofiber membranes with added omniphobic properties, i.e., able to reject almost all kinds of fluid, including low surface tension liquids (see Fig. 20.3). Nanofiber membranes are attractive in this design as the nanofibers themselves provide already rough surfaces, and can be further improved towards reentrant surfaces or to have much lower surface energies to provide omniphobic surfaces (Woo et al. 2017a; Lee et al. 2016; Deng et al. 2018).

Various research groups aimed at making dual-layer membranes, superhydrophobic membranes, and Janus-type membranes for MD. Dual-layer bicomponent composite nanofiber membrane utilizing two wettability properties of both sides of the membrane was prepared and tested for direct MD and obtained high flux of $30 \mathrm{~L} / \mathrm{m}^{2} \mathrm{~h}$ (LMH) (Tijing et al. 2014b). Additional investigation using different dual-layered nanofiber membrane designs were done and tested using air gap MD and compared with commercial membranes, and still obtained very high fluxes and high salt rejection using $3.5 \mathrm{wt} \% \mathrm{NaCl}$ solution as feed (Park et al. 2015). Another study made a different approach, wherein they electrospun polyvinyl alcohol nanofibers incorporated with Triton-X directly on polypropylene (PP) mat. The PP mat, in this case, serves as the hydrophobic layer facing the feed, and the 
Fig. 20.3 (Top) Schematic of the membrane distillation system showing modified nanofiber membrane (SEM image inset) that has omniphobic properties; (bottom) photographic images of liquid droplets on modified nanofiber membrane providing resistance to wicking from liquids with different surface tensions. Adapted from Lee et al. (2016)
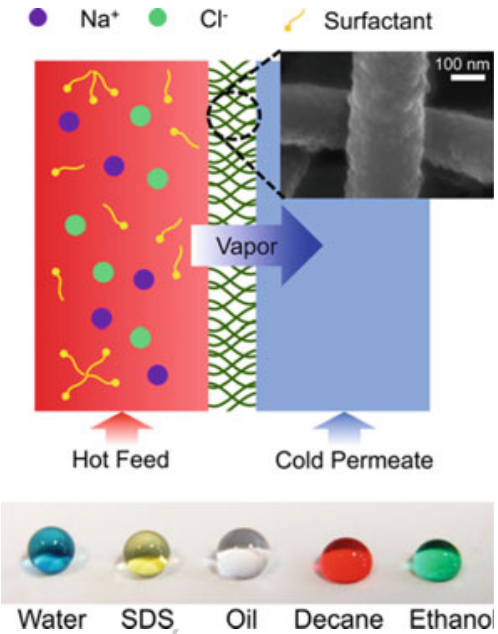

electrospun PVA/Triton-X nanofiber serves as the hydrophilic support layer facing the permeate (Ray et al. 2017). They found 1.5-2 times higher flux of this dual-layer membrane compared with PP mat alone. However, the process mechanism is not clearly elucidated. Nanoparticles are also quite commonly used as nanofillers to improve the nanofiber properties. The incorporation of carbon nanotubes (Tijing et al. 2016), graphene (Woo et al. 2016), $\mathrm{TiO}_{2}$-FTCS (Ren et al. 2017a) into and on nanofibers has added functionality and improved wettability (superhydrophobicity) on the nanofiber membranes that result in improved flux and salt rejection performance even for high salinity brines. Posttreatment of nanofiber membranes has also been found to improve the overall properties of the membrane by increasing its mechanical strength, and enabling smaller and more uniform pore sizes (Yao et al. 2017).

A recent study used nanofibers as a coating material to a hollow fiber membrane via continuous electrospinning for use in MD ( $\mathrm{Su}$ et al. 2017). The hollow fiber membrane served as the collector and the nanofibers were directly collected on the surface of the hollow fiber membranes (see Fig. 20.4). MD performance results of these nanofiber-hollow fiber membranes indicated a good flux of $17 \mathrm{LMH}$ at feed and permeate side temperatures of 60 and $20^{\circ} \mathrm{C}$, respectively. Superhydrophobic titania nanofibers modified with fluorination was recently prepared and tested for its DCMD performance (Fan et al. 2017). The titania nanofibers showed higher flux (12 LMH) and maintained excellent rejection (99.92\%) compared with corresponding ceramic membranes.

Nanofiber membranes for MD pose promising results so far and have been competitive in overall performance compared with existing microfiltration membranes. Still lacking though is the long-term performance tests of most reported nanofiber membranes for MD, and also dealing with scaling and fouling problems when exposed with challenging waters. However, the potential of nanofiber membranes for MD is looking positive, though the issues of energy source and 


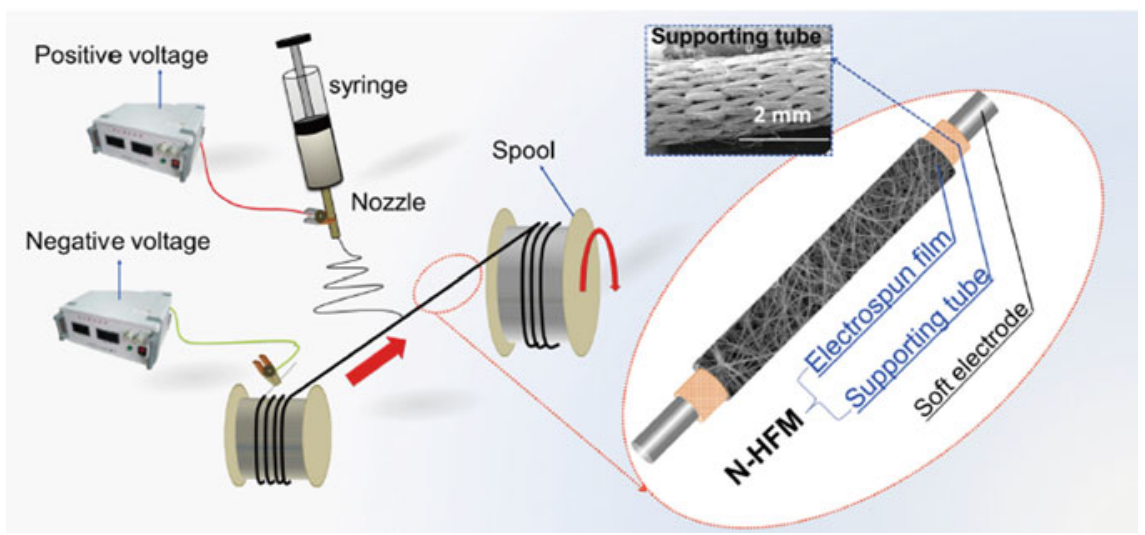

Fig. 20.4 Schematic of the fabrication strategy of directly coating nanofiber onto hollow fiber support Su et al. (2017)

niche application are still some of the challenges to delve more into the MD research space before commercialization will be realized.

Nanofibers as Membrane Support Layer for Forward Osmosis (FO). FO uses a semipermeable membrane between two fluids with different osmotic pressures. This osmotic pressure difference drives the water from the feed solution to pass through the membrane and dilute the draw solution (Phuntsho et al. 2011). Thus, the FO membrane is very essential to the process (Xu et al. 2017). A selective membrane with low internal concentration polarization (ICP) is desirable. There have been promising developments in FO membranes and processes in the last decade. FO membranes are usually made of three parts: very thin selective layer, a middle layer, and a backing/support layer for mechanical stability. In recent years, nanofiber layers utilized as middle or backing layer have been investigated to reduce the ICP effects in FO.

Tian et al. (2017) investigated the effect of silica nanoparticle incorporation on a polyetherimide (PEI) nanofiber support layer of FO membrane subjected to heat-pressing on their FO performance via reduction of ICP effects. The silica/ PEI-supported thin film composite membrane showed higher porosity and pore sizes and exhibited higher osmotic water flux. Their result showed an optimum content of $1.6 \mathrm{wt} \%$ of silica to produce $83 \%$ porosity and the smallest structural parameter of $174 \mu \mathrm{m}$. When deionized water as feed and $1.0 \mathrm{M} \mathrm{NaCl}$ solution as draw solution were used, 42 and $72 \mathrm{LMH}$ were obtained when the active layer is facing the feed, and when the active layer is facing the draw solution, respectively. Park et al. (2018) designed a PVDF nanofiber support layer coated with cross-linked PVA to improve the hydrophilicity of the membrane and overall reduce the ICP effects. Interfacial polymerization was used to make the polyamide sélective layer. Using $1 \mathrm{M} \mathrm{NaCl}$ and deionized water as draw and feed solution, 
respectively, high water flux of 34.2 LMH was achieved using their PVA-coated PVDF nanofiber-supported membrane with structural parameter as low as $154 \mu \mathrm{m}$.

In most laboratory experiments using nanofibers, the nanofibers are designed and produced in the laboratory. However, commercial nanofibers are now available for various applications (e.g., air filtration) and are mostly supported with backing layers. Chowdhury et al. (2017) decided to investigate the use of commercial unsupported nanofiber membrane (from DuPont) to apply interfacial polymerization and tested for FO performance. Interestingly, this nanofiber membrane with selective polyamide layer produced twice the water flux and one-tenth of the reverse solute flux compared with corresponding commercial TFC FO membrane. The mechanical integrity of this nanofiber membrane was also high enough and is even better than typical electrospun materials found in the laboratory.

A promising upscaling strategy for the use of continuous fabrication of nanofiber-supported FO membrane with interfacial polymerization has been reported (Son et al. 2018). In this study, nanofibers were directly electrospun onto a heated $\left(150{ }^{\circ} \mathrm{C}\right)$ collector that sandwiches the nanofiber layer, and then thereafter, interfacial polymerization is applied (see Fig. 20.5). The researchers tested the fabricated thin film nanocomposite membrane in engineered osmosis and obtained high permeability of $30 \mathrm{LMH}$ with excellent selectivity $\left(17 \mathrm{~g} / \mathrm{m}^{2} \mathrm{~h}\right.$ and $\left.0.57 \mathrm{~g} / \mathrm{L}\right)$.

Nanofiber membranes in FO show promising results achieving high fluxes and reduced ICP influence, however, as the FO membrane needs a thin selective layer, the synthesis of the dense polyamide top layer remains a challenge. This is because the structure of the nanofiber layer is not smooth, there is a high tendency for the top selective layer to be delaminated as not all of the surface are adhered well on the crevices or valleys of the overlapping nanofibers. Besides, during the polyamide interfacial polymerization, there is a high tendency for the PA layer to penetrate the pores of the nanofiber membranes which are generally bigger in size. In addition, the mechanical integrity of unsupported nanofiber membrane is also put into

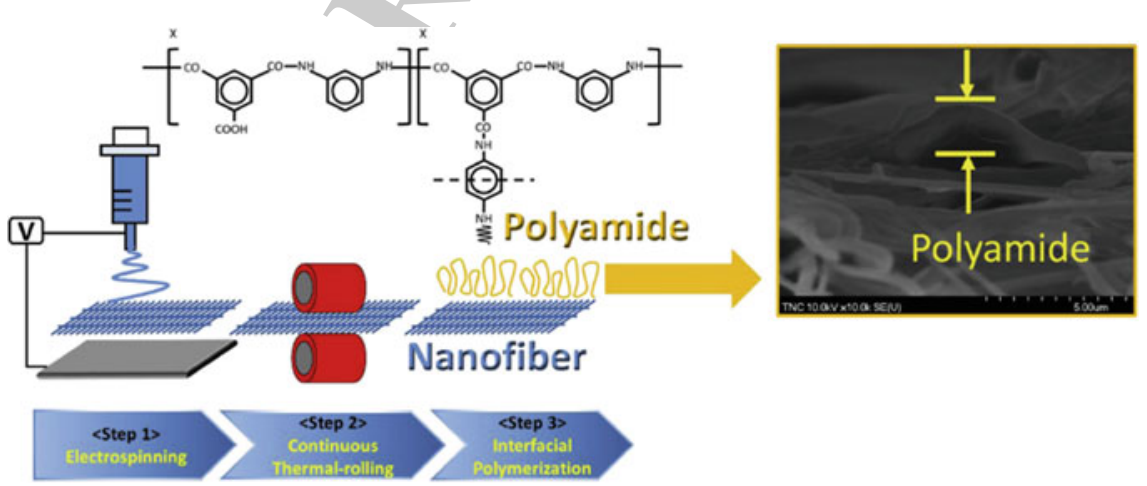

Fig. 20.5 Schematic of the three steps to fabricate thin film nanofiber composite membrane via electrospinning, thermal rolling, and interfacial polymerization. The inset shows the cross section of the fabricated nanofiber support with polyamide layer. Adapted from Son et al. (2018) 
question, thus there is still lots of room for improvement in the use of such nanofibers for FO.

Nanofibers as Electrodes for Capacitive Deionization (CDI). Capacitive deionization is based in electrosorption technique wherein cations and anions from a saline solution are adsorbed on the electrodes via the application of electric potential usually less than $2 \mathrm{~V}$ on two oppositely charged electrodes. The electrosorption behavior is primarily dependent on the electrode material (Porada et al. 2012). The material needs the following properties for it to be ideal for CDI: a) large surface area, large capacitance, high conductivity, high electrochemical stability, and easy to manufacture (Oren 2008). With these electrode criteria in mind, electrospun nanofibers that are carbonized and boasting of high specific surface area are highly potential materials as electrodes. In addition, the ease in adding functionalities to electrospun nanofibers makes them more attractive as electrode materials. Hence, a number of recent research have been conducted on designing nanofiber as electrode materials for CDI.

Among the materials, electrospun porous carbon nanofibers have gained quite an attention for CDI electrode. However, the microporosity of such carbon nanofibers is less desirable as an electrode as it offers resistance to ion transport in inner pores and could act as deep trap sites. Thus, to address this challenge, Wang et al. (2016) developed hierarchical porous carbon electrode with tailored structures for CDI. The structure is a combination of micropore, mesopores, and macropores, which they claim to promote mass transport. Their fabrication strategy was to combine electrospinning with poly(vinylpyrrolidone) template method (Fig. 20.6). The resulting hierarchical porous carbon nanofiber electrode obtained an adsorption capacity of $7.61 \mathrm{mg} / \mathrm{g}$ and the charge efficiency was $23.7 \%$. The adsorption capacity and the charge efficiency were better by 1.87 and 1.51 times, respectively, compared with those of the traditional parallel flow by CDI structure. Another group (Zhang et al. 2018) also synthesized hierarchical porous carbon nanotubes/ graphene/carbon nanofibers obtaining very high salt capacity of $36 \mathrm{mg} / \mathrm{g}$ and large retention absorbing capability of $96.9 \%$. However, the cost of this electrode may be a challenge due to the materials used.

Liu et al. (2016a) investigated the CDI application performance of carbon nanofibers-reinforced 3D porous carbon polyhedral network. The carbon nanofibers were prepared by electrospinning of polyacrylonitrile (PAN) nanofibers as precursor followed by carbonization. This new design of electrode showed an electrosorption capacity of $16.98 \mathrm{mg} / \mathrm{g}$ at $1.2 \mathrm{~V}$ using $500 \mathrm{mg} / \mathrm{L} \mathrm{NaCl}$ solution, which was better compared to baseline electrospun carbon nanofibers. Some metal oxides such as $\mathrm{ZrO}_{2}$ (Yasin et al. 2017), $\mathrm{TiO}_{2}$ (Yasin et al. 2018), and $\mathrm{MnO}_{x}$ (Zhao et al. 2017a) are also available materials for CDI electrodes as they possess properties that are desirable for CDI such as high durability in the aqueous solution, and good hydrophilicity to improve electrode wettability.

Nanomaterials including nanofibers could be promising materials for use as CDI electrodes due to their many interesting properties and functionalities that can lead to improved desalination performance (Gaikwad and Balomajumder 2016). 

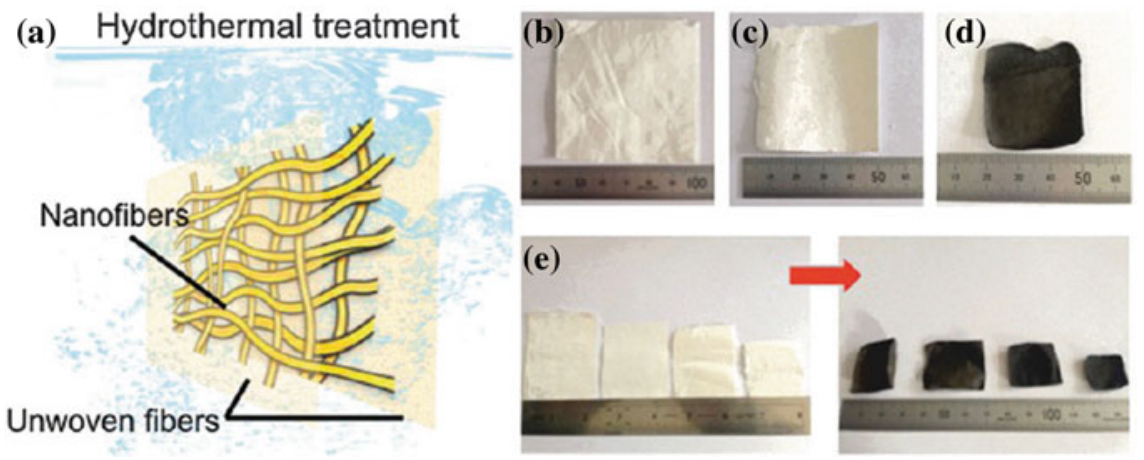

Fig. 20.6 a Schematic of the modified PVP-template method to prepare monolithic porous carbon nanofibers, $\mathbf{b}-\mathbf{e}$ photographic images of PVP nanofibers, PVP-removed porous nanofibers, carbon nanofibers, and porous carbon nanofibers, respectively. Adapted from Wang et al. (2016)

However, many of the studies reported lack economic analysis of the use of such materials, which may increase their cost. Also, the stability of such nanofiber/ nanomaterials needs to be further investigated.

Nanofibers as Barrier/Mid-layer for Reverse Osmosis (RO). RO is considered as the state of the art in desalination and continues to be used for new desalination plants around the world. It has high/desalination efficiency yet it still is a very energy-intensive process (Shenvi et al. 2015). The membrane is the heart of the RO process providing the barrier needed for selective permeation. But aside from being highly selective, the good membrane should minimize fouling formation and should have the high mechanical stability to withstand the high pressure applied to the membrane. Thin film composite membranes, which contain a dense thin selective layer and a porous polymeric support layer, are the most commonly used type of membranes in RO (Xu et al. 2013). Several researches have been done to improve the performance of the RO membrane and one of the recent ones involved the use of nanofibers as an additional layer material of the RO membrane. However, nanofibers are usually not prepared for RO test due to exposure to very high pressure that nanofiber membrane may not be able to withstand.

A recent interesting RO membrane design by Wang et al. (2017a) incorporated ultrafine cellulose nanofibers as the barrier layer, electrospun PAN nanofibers as the mid-layer, and poly(ethylene terephthalate) nonwoven mat as the mechanical support. This makes up as an ultrafiltration membrane, and the addition of the interfacially polymerized polyamide top selective layer makes it a thin composite membrane that can be used for RO application. In addition, the spray coating technique was also utilized to control the thickness of the selective layer during polymerization. This new membrane design with nanofiber incorporation has achieved $96.5 \%$ rejection using $500 \mathrm{ppm} \mathrm{NaCl}$ as feed and a flux of $28.6 \mathrm{LMH}$ under 0.7 MPa pressure, which was comparable with high flux commercial RO membrane. A previous study (Yoon et al. 2009) of the same group also utilized 
PAN nanofibers as middle layer having micropores, and interfacial polymerization was directly done on the surface for use in nanofiltration membranes. This also showed high permeability and comparable selectivity with those of thin composite membranes available in the market.

\section{Nanofibers as Porous Floating Membrane for Solar Steam Generation.}

Desalination, in general, is still an energy-intensive process, thus as a way to reduce energy cost while maintaining good process efficiency, solar desalination comes into the picture. Solar desalination, in this case, refers to the use of solar energy as a heat source to separate water molecules from the salts and impurities via evaporation-condensation process. Solar distillation process has been used for a long time by just simply exposing a wide area of seawater to the sun, and letting the evaporation to occur, and capturing the vapors via a cooling plate to condense back to pure water (Kabeel and El-Agouz 2011). However, this process takes a long time to occur as the mechanism is based on bulk heating rather than just surface heating of the surface water. Recently, a few studies were carried out designing floating materials on the saline water, wherein the floated porous materials have the ability to absorb solar heat and heat itself up thereby providing localized heating of the interface between the material and surface water, enabling more rapid evaporation (Wang 2018). The water then passes through the porous structure of the material and proceed with the condensation (Chen et al. 2018a; Zhou et al. 2016a). Nanofiber membranes with or without photonic or light-absorbing particles have been tested for such application.

Chen et al. (2018a) investigated the efficacy of a nanofiber-based composite film loaded with plasmonic gold nanoparticle on its solar steam generation. Figure 20.7 shows the schematic of the solar generation process and the new nanofiber-based membrane for solar steam generation. With the very good mechanical stability of the nanofiber film, the evaporation rate was found to be $1.424 \mathrm{~kg} / \mathrm{m}^{2} \mathrm{~h}$ with a solar vapor efficiency of $83 \%$ when exposed to one sun exposure. They also claimed that
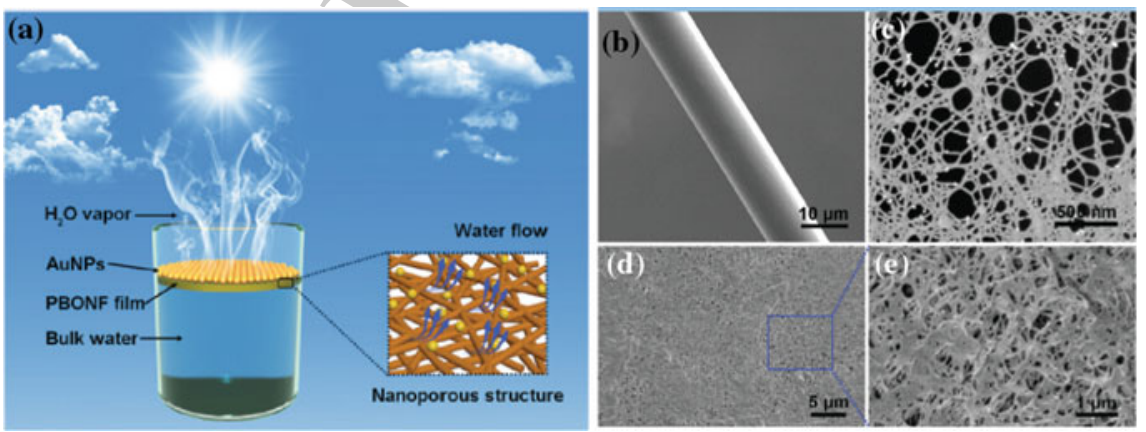

Fig. 20.7 a Schematic of the solar-driven steam generation using nanoporous AuNP/poly(pphenylene benzobisoxazole) (PBO) nanofiber composite films. SEM images of $\mathbf{b}$ PBO microfiber, c PBO nanofibers and its $\mathbf{d}$ top and $\mathbf{e}$ surface views. Adapted from Chen et al. (2018a) 
the material can be readily reused, hence indicating its promising potential for clean water production, even to the point of suggesting that it can be used in space environments.

Nanofibers Adsorbent or Filters for Contaminant Removal from Water. With exploding population and rapid development in agriculture, manufacturing, and mining, the availability and use of more products like pesticides, fertilizers, chemicals, and heavy metals have led to increased leakage/discharge their constituents into groundwater. Such contaminants, which are very complex and difficult to eradicate, can seriously influence the ecosystem in groundwater, aquifers, and soil. Therefore, developing groundwater remediation strategies is of high necessity to address the challenges in the increasingly serious groundwater pollution.

Groundwater remediation technologies are basically classified into two ways: pump and treat technology (P\&T) and in situ remediation technology. For P\&T (Truex et al. 2017), contaminated groundwater is pumped out from the aquifer and then treated externally in a treatment building. Thus, all the surface water treatments such as adsorption, filtration, and advanced oxidation processes (AOPs) can be utilized for groundwater remediation. This also opens up for the possibility of using nanofibers as main or substrate material for the mentioned treatment processes that can be utilized for P\&T groundwater remediation.

For in situ groundwater remediation, methods are very limited due to the complex geological conditions, difficulties in construction, and the instability of sampling and detection. Classical treatments include permeable reactive barrier (PRB) technology and direct injection of adsorbents, oxidizers, or reducing agents. As nanofibers can be made into membranes, they can also be potentially utilized as materials for PRB that can be placed into the aquifer to block the plume and treat groundwater.

Nanofiber for groundwater remediation can be used in two forms based on the dominant role in the treatment process. One is to utilize nanofiber itself to remove contaminants in the groundwater. The other is to employ the nanofiber as a carrier or substrate to facilitate immobilization of the existing materials/technologies used for groundwater remediation. For example, nanofibers have been used in adsorption and filtration due to their high specific surface area and easy surface functionalization. (Haider et al. 2015). Heavy metals (like chromium, copper, cadmium, lead, arsenic, and mercury) and organic pollutants (chloride organics, dyes and etc.) are the main contaminants in groundwater generally remediated by adsorption process (Aliabadi et al. 2013). Adsorption works mainly via affinities (like physical affinity, electrostatic interaction, chemical chelation, and complexation) between contaminants and functional groups on adsorbents (Huang et al. 2014). Studies have shown that polymers containing different functional groups such as amino, carboxyl, phosphoric, etc., have good complexation affinities toward metals ions and were commonly sélected to fabricate nanofibers for heavy metal adsorption (Haider et al. 2015). Polyacrylic acid (PAA) with a large number of - $\mathrm{COOH}$ group is widely used as a complexing agent. Many researchers introduced PAA into nanofiber and use it 
for heavy metal adsorption. Chitpong and Husson (2017) grafted PAA polymer onto poly(glycidyl methacrylate) (PGMA) nanofiber and the fabricated PAA-PGMA membrane obtained good removal of cadmium with maximum capacities that exceeded $160 \mathrm{mg} / \mathrm{g}$. Xiao et al. employed electrospun PAA/PVA nanofibers for the removal of metal ions from aqueous solution. The nanofiber membrane showed the exceptional removal of copper ions (91\% removal within $3 \mathrm{~h}$ ) and it also showed superb selectivity in the presence of calcium ions (Xiao et al. 2010).

Nanofiber can also be fabricated as membranes used into filtration process for groundwater remediation. Permeability, rejection capability, and service life are the three most important factors for the selection of membrane in filtration process. Permeability and rejection capacity are mainly determined by pore size, porosity, surface charges, and hydrophilicity. Pore size and porosity can basically be controlled by changing the fiber size of nanofiber membrane. Electrospun nanofiber can easily be manipulated to control fiber size from nanoscale to microscale by changing polymer concentration, introducing additives or adjusting electrospinning parameters. Therefore, some studies have reported using electrospun nanofiber membranes into microfiltration (MF) and ultrafiltration (UF) processes. Bae et al. (2016) fabricated a polyethersulfone (PES) electrospun nanofiber membrane and employ the membrane into MF for the removal of bovine serum albumin (BSA). Wang et al. (2017b). electrospun regenerated cellulose nanofiber membranes surface-grafted with water-insoluble poly(HEMA) or water-soluble poly(AAS) chains via the ATRP method for ultrafiltration of water. The surface hydrophilicity of the nanofibers can be modified by introducing materials with hydrophilic functional groups such as $-\mathrm{COOH}$ and $-\mathrm{OH}$. Jang et al. (2015) introduced graphene oxide ( $\mathrm{GO}$, with $-\mathrm{COOH}$ and $-\mathrm{OH}$ ) into electrospun polyvinylidene fluoride (PVDF) nanofiber for MF process and the PVDF-GO achieved three times improvement in permeation flux. For the removal of charged contaminants, surface charges on the nanofiber can be modified by introducing charged polymer. Interestingly, for the adsorption process, nanofibers should be introduced with opposing electrical charge to contaminants for a better attraction and immobilization of contaminants. However, on the contrary, for the membrane filtration process, nanofibers are expected to have same electrical charge with contaminants to increase the rejection of contaminants and alleviate membrane fouling from the affinity of foulants by electrostatic repulsion effect. Han et al. prepared a surface-charged PVDF nanofiber MF membrane through a direct sulfonation reaction, which both increased the rejection of contaminants and reduced the fouling by improving electrostatic repulsion between membrane surfaces and charged polystyrene (PS) latex suspensions as feed solution (Han et al. 2011).

However, individual nanofibers have some restrictions and are not adequate to cope in treatment with all the contaminants in groundwater. Incorporating with other materials/technologies in the existing groundwater remediation can both improve the performance of nanofiber and existing remediation technology. For instance, nanoscale zero-valent iron particles (nZVI), with its the high reactivity towards a broad range of contaminants, have been a commonly used material/ 
technology for in situ groundwater remediation (Tosco et al. 2014). However, nZVI particles themselves are prone to agglomeration and sedimentation (Xue et al. 2018; Liu et al. 2014a). Traditional methods to combat agglomeration are to add surfactants (Tian et al. 2018), and stabilizers (Schiwy et al. 2016) to maintain the uniformity and activity of nZVI particles. Nevertheless, those auxiliary additives and contaminants adsorbed on nZVI may be released and can be a source of secondary pollution if not properly retrieved (Lefevre et al. 2016). Electrospun nanofiber membrane with its high specific surface area, recyclable and easily functionalized properties is an ideal material for nZVI immobilization to avoid agglomeration and sedimentation. With nanofibers as carrier, it provides an opportunity for regeneration of the membrane, thus avoiding the release of nZVIs and potential secondary pollution. (Yang et al. 2014). A study by Liu et al. (2014b) immobilized nZVI onto polyacrylonitrile (PAN)-based oxidized mat to reduce water contaminants (including methylene blue and trichloroethylene), and their results showed excellent performance on the removal of the target contaminants. Another study reported on the use of chitosan fiber-supported nZVI particles, which showed excellent sorption performance for inorganic arsenic uptake at concentration ranging from 0.01 to $5.00 \mathrm{mg} / \mathrm{L}$ (Horzum et al. 2013). Ren et al. (2017b) successfully immobilized $48.8 \mathrm{wt} \%$ nZVI onto a high ratio of PAA/PVA nanofiber mat and the nZVI-PAA-PVA had high removals to both methylene blue and copper ions.

Nanofiber can also be a support layer for other filtration processes or active layer based on other materials. Bahmani et al. (2017) employed electrospun polyethylene terephthalate (PET) nanofiber scaffold as a support layer to increase mechanical strength and fabricated PAN nanofiber as an active layer onto the PET scaffold. The thin film composite (TFC) membrane showed $172-520 \%$ higher flux and improved rejection of arsenate ions when compared with the UF membrane.

For the risk control of potential pollution from nanofiber, researchers also developed biodegradable and recyclable nanofiber to avoid secondary pollution. Varanasi et al. (2015) developed a biodegradable and recyclable cellulose nanofibre composite, which showed a decent water flux of $80 \mathrm{LMH}$ and MWCO of $200 \mathrm{kDa}$ in UF process.

The interesting and desirable properties of nanofibers such as large specific surface area, controllable fiber sizes, ease of fabrication, high flexibility to surface modification, and strong compatibility with other technologies make them highly potential for use in water treatment and groundwater remediation. However, still there are a number of challenges that need to be addressed on the use and design of nanofibers, for example, generally weaker mechanical properties, the less tested long-term performance and stability, mass production issues, among others, thus continuous and more rigorous research are still needed to fulfill its promising potential. 


\subsubsection{Nanofibers for Wastewater Treatment}

Nanofibers as Membrane for Membrane Bioreactor (MBR). The feasibility of using nanofiber membranes for MBR application has recently been investigated by several groups. Nanofiber membranes share similar pore sizes with MF membranes in the range of $0.1-10 \mu \mathrm{m}$, making them applicable for MBR process which uses MF membranes. Bjorge et al. were the first group to investigate the performance of nanofibrous membranes in MBR application (Bjorge et al. 2009, 2010). They utilized polyamide (PA) nanofibers for their MBR process. Based on their results, they found that nanofibers suffered rapid decay of flux because of the irreversible fouling formed on the electrospun membrane. The PA nanofibers were also found to have low removal efficiency for pathogen removal, even though the integration of $\mathrm{Ag}$ nanoparticles promoted the removal of Gram-negative bacteria. Their report did not provide much positive result on the use of nanofiber membranes but gave a glimpse of potential opportunities for improving the nanofiber design and properties. Later, Bilad et al. improved the nanofibrous PA membrane performance in MBR by heat-treating the membranes (Bilad et al. 2011). Rapid flux decay was prevented, as the heat treatment greatly improved the integrity and mechanical strength of the nanofiber membranes; hence, the heat-treated electrospun membranes showed comparable flux performance to the commercial membranes (Fig. 20.8). Also, their use of more hydrophilic PA6 improved the permeation flux in MBR. However, the authors suggested further studies on the electrospun membrane improvement as the heat-treated nanofibrous membranes still suffered the intrusion of sludge in long-term operation, which led to the gradual increase in the fouling formation. Moradi et al. developed electrospun membrane using PAN, a polymer with high mechanical and thermal stability. Moreover, PAN is also one of the easiest

Fig. 20.8 The flux stepping profiles of electrospun and commercial membranes (Bilad et al. 2011)

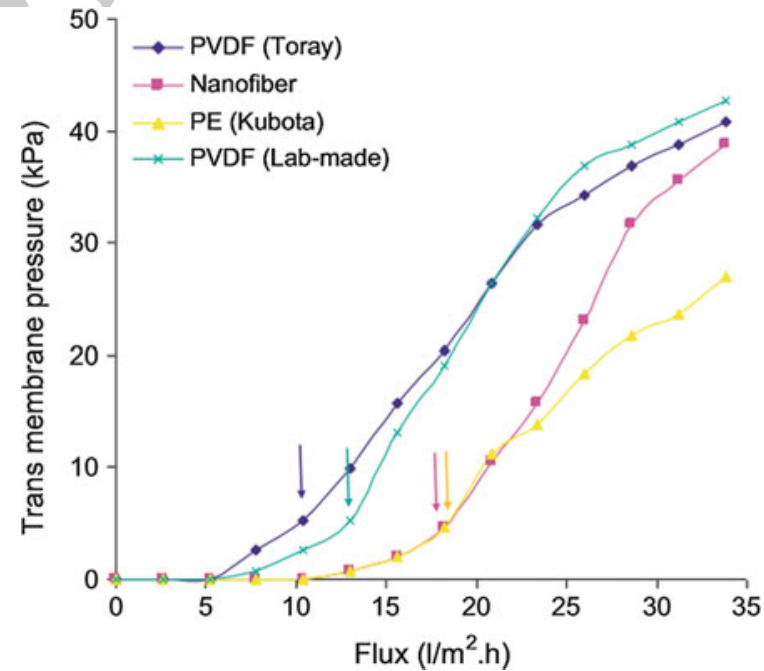


polymers to electrospin to fabricate nanofiber membranes (Moradi et al. 2018). The authors also considered high fouling resistance of PAN to be an interesting property that is attractive for MBR application. The antifouling resistance of PAN membranes was further improved with the aid of fumarate alumoxane nanoparticles, integrated into the membrane matrix. The nanoparticles, at optimal concentrations, greatly improved the fouling resistance by increasing the hydrophilicity of the membranes, owing to the rich hydroxyl and carboxylate groups on the nanoparticle surfaces. However, too high concentration of the fumarate alumoxane nanoparticles also led to aggregation, blocking nanofibrous membrane pores, and hence reduced permeation flux in MBR (Moradi et al. 2018). Overall, the PAN nanofibrous membranes loaded with nanoparticles showed promising performance with greatly reduced irreversible fouling in MBR.

Nanofibers as Membrane or Adsorbent for Oil-Water Separation. Owing to frequent oil spill accidents in recent years, there is an increasing need for novel and efficient technologies for oil/water separation. Gravity-driven membrane separation, an energy-efficient versatile technology, is generally considered one of the most promising technologies (Arslan et al. 2016). For proper separation of oil and water emulsion using gravity-driven method, one important factor needed for the separation materials is the engineered surface wetting properties, either to be superhydrophobic and superoleophilic, or superhydrophilic and underwatersuperoleophobic. Electrospinning is a desirable technique to produce membranes with pore size, and pore size distribution suitable for gravity-driven applications, which also boast of ease in surface modification and functionalization. The relatively easier approach to fabricate membranes for oil/water separation was to directly electrospin low surface tension polymer membranes; polystyrene, polyvinylidene fluoride, or polytetrafluoroethylene membranes had been fabricated in one-step electrospinning (Kim et al. 2013; Zhou and Wu 2015; Qing et al. 2017). Although without modification, these membranes showed superhydrophobic and superoleophilic properties, thus performing efficiently in oil/water separation process. Some other researchers developed approaches to impart superhydrophobicity and superoleophilicity to the hydrophilic membranes by surface modifications. Li et al. coated the silver nanocluster on the nanofibrous PAN membranes, followed by superhydrophobization; thus, a high contact angle and low sliding angle of water were realized, and the membranes could treat the oily wastewater for 30 cycles with good stability ( $\mathrm{Li}$ et al. 2014). Arslan et al. developed perfluoro-modified electrospun cellulose acetate membranes through sol-gel methods; the modified membranes had a high water contact angle but low oil contact angle, which worked well in oil/water separation for 5 cycles (Arslan et al. 2016). Chen et al. chose the elastic polyurethane and chromatic polydiacetylenes for electrospinning because of their high mechanical stability and chemical resistance; after UV treatment, and later on heat treatment, the membranes became superhydrophobic with water contact angle higher than $155^{\circ}$, which could remain stable even after 1000 stretching cycles. The elastic nanofibrous membranes maintained high removal efficiency for 12 cycles (Chen et al. 2018b) (Fig. 20.9). Liu et al. improved the hydrophobicity of PVDF 
nanofiber membrane through incorporating $\mathrm{ZnO}$ nanoparticles and fluorination posttreatment. These modification processes made the nanofiber membranes superhydrophibic (water contact angle of $171^{\circ}$ ) while maintaining the oil contact angle of $0^{\circ}$ (Liu et al. 2016b). The modified PVDF membrane showed much improved antifouling resistance and oil/water separation efficiency for dozens of cycles. One research group investigated electrospun membrane formed from carbonaceous materials, as they argued that the polymer membranes were prone degradation from chemical cleaning, which is necessary in oil/water separation (Tai et al. 2014). $\mathrm{SiO}_{2}$-Carbon membranes were fabricated using electrospinning, and after being coated with silicone, the inorganic membrane became superhydrophobic and superoleophilic, while maintaining its high chemical and thermal stability. The other benefit of such membrane was that, unlike polymer membranes, its wettability was not affected by $\mathrm{pH}$ of the wastewater.

The other approach of gravity-driven membrane separation for oil/water separation was using superhydrophilic and underwater-superoleophobic membrane. To achieve such membrane surface property, surface modification was necessary.
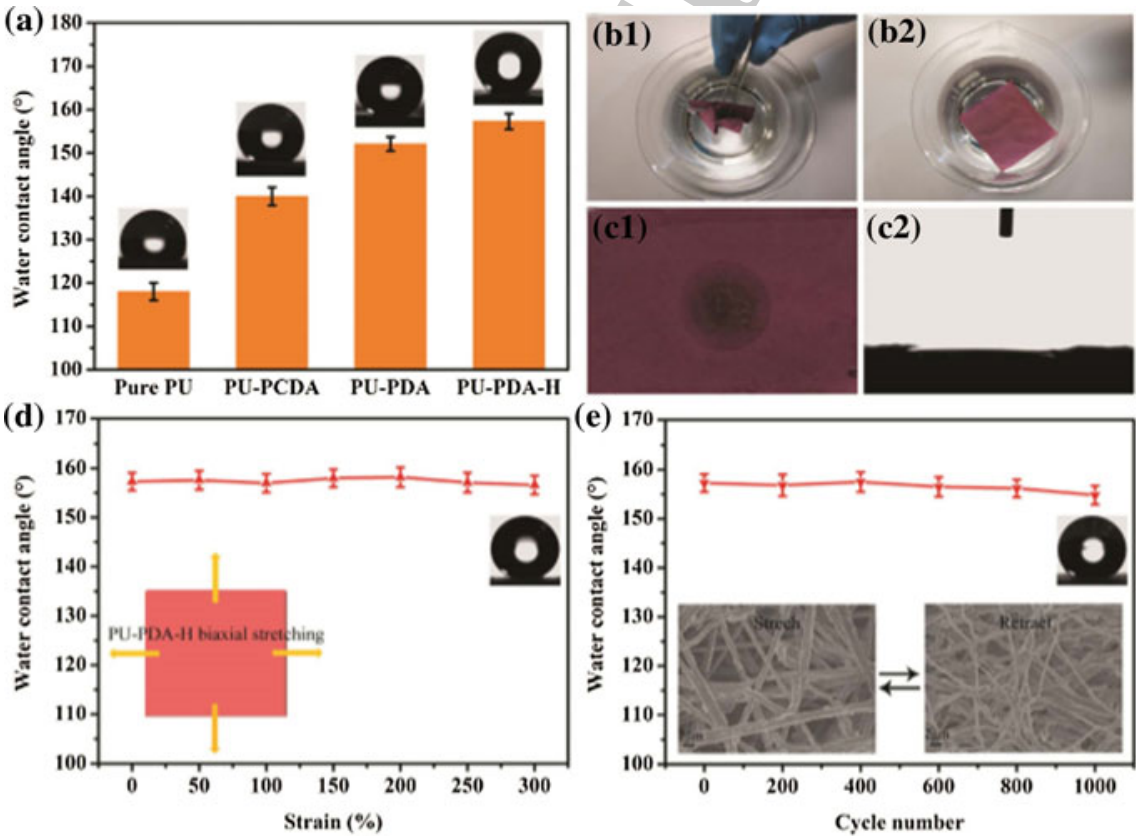

Fig. 20.9 a Water contact angle of different PU membranes; $\mathbf{b}$ immediate rising of PDA-modified PU membranes, which is immersed in water by an external force; $\mathbf{c}$ photograph of an oil droplet on PDA-modified PU membrane with oil contact angle of $0^{\circ}$; d water angle of PDA-modified PU membranes under various strains, and the inset shows the schematic of membranes under biaxial stretching; e water contact angle of PDA-modified PU membranes after 1000 stretching cycles, and the inset shows the SEM images of stretched and retracted membranes after 1000 stretching cycles (Chen et al. 2018b) 
Ahmed et al. directed coated cellulose-ionic liquid solution on electrospun PVDF membrane to modify its surface properties. This led to superhydophilic property (water contact angle of $0^{\circ}$ ) and superoleophobic underwater (dichloromethane contact angle of $169^{\circ}$ underwater) (Ejaz Ahmed et al. 2014). The membranes showed high separation efficiency for most types of oil. Obaid et al. modified the polysulfone electrospun membranes surface by generating one thin layer of polyamide on top, and its contact angle of water dropped from $130^{\circ}$ to $13^{\circ}$ (Obaid et al. 2015). The membrane maintained three consecutive cycles of high water flux in oil/ water separation. Hydrophilic inorganic additives, $\mathrm{SiO}_{2}$, and graphene oxide had also been individually incorporated into the electrospun nanofibrous membranes, and hence greatly decreased the contact angle of water (to around $20^{\circ}$ ). These membranes had improved oil/water separation efficiency and durability (Zhang et al. 2017; Islam et al. 2017). Membrane surface with hierarchical structure was achieved on the cross-linked polyacrylonitrile/hyperbranched polyethyleneimine electrospun membranes; thus, it had a water contact angle of $0^{\circ}$ and underwater oil contact angle of $163^{\circ}$. The composite membranes achieved strong antifouling property, so it maintained high flux and rejection in 10 cycles (Wang et al. 2018).

For the sake of improved versatility with a controllable surface wettability, smart materials were introduced in the electrospun nanofibrous for gravity-driven oil/ water separation membranes. Responsive to the $\mathrm{pH}$ of the wastewater, these membranes could switch between superhydrophobic/superoleophilic and superhydrophilic/underwater-superoleophobic (Li et al. 2015; Cheng et al. 2017). In addition, incorporated with decanoic acid, the modified electrospun polyimide membrane could become superhydrophilic from superhydrophobic, if exposed to ammonia vapor (Mino et al. 2017).

\section{Nanofibers as Omniphobic Membrane for Produced Water Treatment.}

Produced water, mainly from oil field or gas field, is becoming a major challenge for wastewater treatment under current tightening environmental regulation, as its high total dissolved solids make reverse osmosis, the currently most efficient water separation technology, impractical (Woo et al. 2017b). Therefore, membrane distillation, one of few technologies able to treat highly saline wastewater, was being developed as a solution. However, low surface tension compounds and oil emulsion, commonly found in the produced water, made the hydrophobic membrane susceptible to membrane wetting, which could greatly affect the permeation performance and even halt the operation (Yao et al. 2018). Due to its controllable pore size range and ease of modification, electrospun nanofiber membranes were developed into barriers with anti-surfactant and anti-low-surface-tension-compound properties. Till now, two major approaches were established: (1) Omniphobic membrane surface; (2) Janus membrane (superhydrophilic and underwater oleophobic surface layer with superhydrophobic or omniphobic bottom layer). Through $\mathrm{CF}_{4}$ plasma treatment, Woo et al. modified the electrospun PVDF membrane to obtain omniphobicity on its surface (Woo et al. 2017b). The omniphobic membrane had high contact angle of both water and low surface tension liquids (mineral oil and methanol), as well as a greatly decreased water sliding angle to $50^{\circ}$ if the membranes had been 
plasma-treated for more than $15 \mathrm{~min}$. When treating real produced water containing high concentrations of surfactant in the configuration of DCMD, while the commercial membrane suffered rapid wetting, the modified electrospun membranes had no wetting issues and maintained stable flux and $99.99 \%$ salt rejection. Alternately, coating $1 \mathrm{H}, 1 \mathrm{H}, 2 \mathrm{H}, 2 \mathrm{H}$-perfluorodecyltriethoxysilane followed by heat treatment could impart omniphobicity to PVDF-HFP nanofiber membranes (An et al. 2018). The modified membrane had high contact angle for both water and oil, and the property of omniphobicity was robust even under harsh circumstances. Without an expense to performance, the omniphobic membrane successfully treated the produced water containing surfactant of sodium dodecyl sulfate for more than $2 \mathrm{~h}$. Electrospun inorganic membranes could be modified to acquire omniphobicity as well. Huang developed omniphobic silica-based membranes with high surfactant resistance (Huang et al. 2017a). The omniphobicity of membrane was contributed by two factors: reentrant structures induced by coaxial technique (sheath solution for second scale nanostructure), and low surface tension after being dip-coated in $1 \mathrm{H}, 1 \mathrm{H}, 2 \mathrm{H}, 2 \mathrm{H}$-perfluorodecyltriethoxysilane. The omniphobic electrospun silica membrane had very high contact angle and stable MD performance against wetting when treating produced water containing surfactants.

To further improve the wetting resistance, Huang et al. developed a Janus membrane containing an omniphobic substrate (Huang et al. 2017b). PVDF-HFP membrane substrates containing cetyltrimethylammonium bromide were fabricated using electrospinning, and coated with fluorinated silica nanoparticles thus the substrate became omniphobic. Then, a layer of silica nanoparticles, chitosan, and perfluorooctanoate was spray-coated on the omniphobic substrate, forming a Janus membrane. The Janus membranes, showing greatly improved wetting and fouling resistance against troublesome compounds (oil emulsion and surfactant) in the produced water, had no degradation of flux and rejection performance for $10 \mathrm{~h} \mathrm{MD}$ operation. An alternate approach to form a hydrophilic layer in a Janus membrane was electrospinning. A nanofibrous network comprising both cellulose acetate and silica nanoparticles could be simultaneously coated on a hydrophobic PTFE substrate in one-step electrospinning; a low water contact angle of $40^{\circ}$ and high underwater oil contact angle of $154^{\circ}$ were achieved (Hou et al. 2018) (Fig. 20.10). For $30 \mathrm{~h}$, the electrospun-modified Janus membrane had stable performance treating saline water which/contained oil-in-water emulsion.

\section{Nanofibers as Membrane or Adsorbent for Dye Wastewater Treatment.}

Organic dye contaminants, greatly found in textile wastewater, posed great risks to both ecological system and human health. As these contaminants had high resistance against heat, and oxidizing light, treatment before their discharge was the best approach to minimize their impacts. Various physiochemical treatment processes, including adsorption, filtration, coagulation-flocculation, biological treatment, chlorination, electrochemical, and photocatalytic degradation, had been developed (Chen et al. 2018c). Membrane electrospinning has simple manufacturing processes and could conveniently acquire various functions with controllable pore sizes; thus, 
Fig. 20.10 Normalized permeate flux for the commercial PTFE membrane and the fabricated composite membranes in the DCMD experiments. The saline oil-in-water emulsion with $600 \mathrm{mM} \mathrm{NaCl}$ and $1000 \mathrm{mg} / \mathrm{L}$ crude oil was used as the feed. The flow rate at feed and permeate side were 70 L/H (Hou et al. 2018)

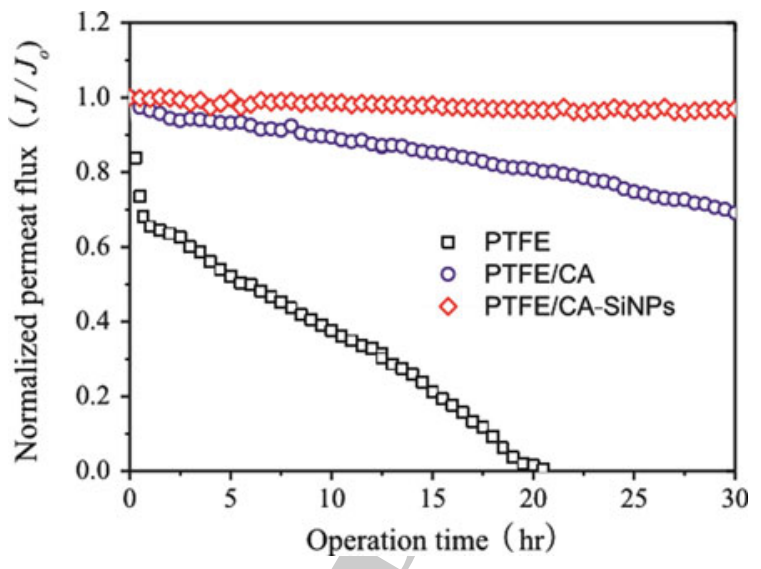

a great number of dye treatment technology had been developed based on electrospun nanofiber membranes.

Direct filtration had been developed to separate the dye compounds from the water. Zhao fabricated $\beta$-cyclodextrin-based electrospun membranes which had a high flow rate of $150 \mathrm{ml} / \mathrm{min}$ for five cycles when separating cationic dye methylene blue from anionic dye methyl, owing to the strong electrostatic repulsion between the carboxyl groups on the membrane and the negative electricity of anionic dyes (Zhao et al. 2015a). Incorporating graphene oxide in the PVDF spinning solution, Ghaffar et al. developed a membrane having $99 \%$ selectivity towards cationic dyes with a flux of 439 LMH (Ghaffar et al. 2018). On the other side, electrospun membranes had been specifically designed to reject the anionic dyes by incorporating nanomaterials in the hydrophilic membranes. With the addition of $0.5 \mathrm{wt} \% \mathrm{SiO}_{2}$ in the spinning solution, the PVA nanofiber membrane was able to remove $98 \%$ of Direct Red 23 with a high flux of 1711 LMH (Hosseini et al. 2018). Coated with graphene oxide with the aid of polydopamine, the electrospun PEN membrane was able to remove $92.6 \%$ Direct Blue 14 with a flux of 141.5 LMH (Zhan et al. 2018). Electrospun membranes capable of removing both cationic and anionic dyes were also developed. Shi and coworkers fabricated branch-like carboxylated MWCNTS/Chitosan nanofiber membranes; they had high rejection of both methylene blue (86\%) and methyl orange (83\%) while maintaining high flux higher than 3500 LMH (Shi et al. 2016). Multilayer electrospun nylon-6 membranes were the alternate approach to achieve such rejection. With greatly decreased pore size owing to multilayer and increased thickness, the nanofiber membranes achieved high removal rejection with relatively low flux of $16 \mathrm{LMH}$ (Yu et al. 2018). Incorporated with graphene oxide, the multilayer nylon nanofiber membranes had improved rejection of both methylene blue (99\%) and methyl orange (95\%) without sacrificing the flux performance (Chen et al. 2018c). Treating dye wastewater via MD with electrospun membrane was also explored. PDMS/ PVDF nanofiber membrane showed high flux and rejection rate and greatly reduced irreversible fouling when treating anionic crystal violet (Vaselbehagh et al. 2017). 
Electrospun membranes could be used as adsorbents, another approach treating dye in the wastewater. Some researchers used the nanofibers as carriers of adsorbents, and poly (vinyl alcohol) (PVA) was the most common one. Various adsorbents, including poly (acrylic acid), graphene oxide, polyethyleneimine, and chitosan, had been coated on the PVA membranes; these adsorbent membranes had high adsorption capacity in multiple consecutive cycles (Yan et al. 2015; Xing et al. 2017; Zhu et al. 2017; Habiba et al. 2017a). To improve durability, Gopakumar et al. developed adsorbent membrane based on PVDF membranes (Gopakumar et al. 2017). Cellulose acetate nanofiber was incorporated into PVDF membranes and modified by Meldrum's Acid; thus, the membrane obtained a high adsorption capacity of crystal violet of $3985 \mathrm{mg} / \mathrm{g}$. After modification, the nanofiber membranes alone could work as adsorbent. Amine-modified electrospun polymer membranes could adsorb methyl orange at a capacity of $312.5 \mathrm{mg} / \mathrm{g}$ (Satilmis and Uyar 2018). Although having lower adsorption capacity of methylene blue than the electrospun polymer adsorbent membranes, inorganic electrospun membranes made of zeolites were successfully fabricated; they were easier and faster for separation and reuse than the raw form of the minerals (Saepurahman and Hashaikeh 2015).

Similar to the adsorbent membrane, the electrospun nanofiber membranes could work as carriers of the nanoparticles that photo-degrade the dyes. Li et al. incorporated $\mathrm{TiO}_{2}$ nanoparticle, a photocatalyst, on electrospun poly (methylmethacrylate) membranes, which degraded Methylene Blue stably in 5 consecutive cycles ( $\mathrm{Li}$ et al. 2017a) (Fig. 20.11). Others coated $\mathrm{Ag} @ \mathrm{AgCl}$ or $\mathrm{H}_{4} \mathrm{SiW}_{12} \mathrm{O}_{40}$ on electrospun cellulose acetate membranes, and the membranes degraded methyl orange efficiently in three successive cycles (Zhou et al. 2016b; Li et al. 2017b). Electrospun membranes made of inorganic photocatalyst materials was a more direct approach to remove the dyes in wastewater. PVP (or PVA) is generally used as a temporary carrier in the electrospinning process and is burned off after the membranes are formed. Various materials, such as $\mathrm{MoS}_{2}, \mathrm{TiO}_{2}$, and $\mathrm{SiO}_{2}$, can be made into inorganic nanofiber membranes (Ren et al. 2018; Singh et al. 2017; Yang et al. 2017; Wang et al. 2017c). To improve the degradation efficiency, additional particles $\left(\mathrm{CoFe}_{2} \mathrm{O}_{4}, \mathrm{Pt}\right.$, and $\left.\mathrm{MnO}_{2}\right)$ were incorporated to impart hierarchical structure to the membrane surface. The inorganic membranes were able to degrade the dyes in multiple cycles. Also, activated carbon nanofiber membranes can degrade dyes. Electrospun membranes made of PAN, a precursor of activated carbon, had porous hierarchical structure (Zhu et al. 2018; Lin et al. 2017) after exposing to high thermal treatment. Also, the oxidation power of the carbon materials could be enhanced by the incorporation of cobalt into the spinning solution (Lin et al. 2017). After carbonization, the nanofibrous membranes could degrade the dye efficiently in five consecutive cycles.

Nanofibers as Adsorbent for Removal of Heavy Metal Ions from Water/ Wastewater. Heavy metal pollutants in the wastewater pose serious challenges to human health because they are highly carcinogenic and hard to be decomposed or biodegraded. Adsorbents had been developed to deal with the threat; however, regeneration of the conventional adsorbents has serious difficulties. Due to their 
Fig. 20.11 Photodegradation of methyl orange by $\mathrm{TiO}_{2} @ \mathrm{PMMA}$ during in five consecutive cycles (dye concentration at $10 \mathrm{mg} / \mathrm{L}$ ) (Li et al. 2017a)

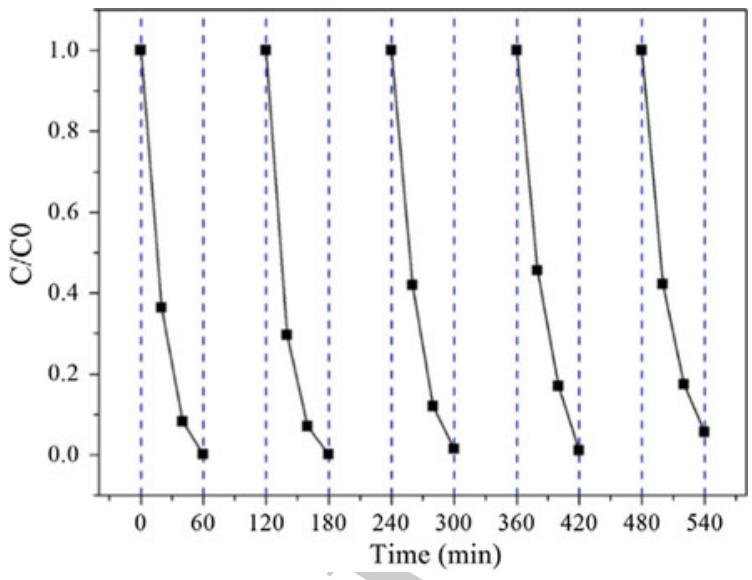

tunable pore size, high surface to volume ratio, and integrity, electrospun membranes were considered suitable as adsorbent of heavy metal ions from wastewater (Li et al. 2018).

Chitosan, capable of binding heavy metal ions, had been selected to fabricate electrospun membranes. To increase the adsorption capacity, PVA or poly (ethylene oxide) (PEO) was mixed with chitosan in the spinning solution; hence, the electrospun nanofiber membranes had increased pore size owing to decreased crystallinity ( $\mathrm{Li}$ et al. 2018; Habiba et al. 2017b; Shariful et al. 2017). To further enhance the adsorption capacity of chitosan membranes, various additives, including zeolite, halloysite nanotubes, and graphene oxide, had been used (Hadi Najafabadi et al. 2015). The chitosan-based electrospun membranes achieved a high removal efficiency of $\mathrm{Cr}(\mathrm{VI}), \mathrm{Cu}(\mathrm{II}), \mathrm{Pb}$ (II), $\mathrm{Zn}$ (II), and $\mathrm{Fe}(\mathrm{III})$ in multiple cycles. Also, chitosan, cross-linked with rectorite, could be loaded onto electrospun nanofiber substrate by electrospinning simultaneously. Huang et al. developed chitosan-rectorite nanospheres embedded in aminated PAN nanofiber membranes to efficiently treat $\mathrm{Pb}$ (II) (Huang et al. 2018); Tu and coworkers also fabricated chitosan-rectorite nanospheres embedded polystyrene (PS) membranes to adsorb $\mathrm{Ca}$ (II) (Tu et al. 2017). Even without additives, PS membranes alone exhibited impressive adsorbent properties.

Alcaraz-Espinoza et al. developed hierarchical composite membranes by applying polymerization of polyaniline on the PS nanofiber membranes; the membranes could remediate $\mathrm{Hg}(\mathrm{II}), \mathrm{Cd}(\mathrm{II}), \mathrm{Pb}(\mathrm{II}), \mathrm{Cr}(\mathrm{VI})$, and $\mathrm{Cu}$ (II) ions efficiently (Alcaraz-Espinoza et al. 2015). Due to their high mechanical strength, PAN nanofiber membranes had been greatly used as the base/substrate of the membrane adsorbent. Zhao and colleagues developed an amino-rich hydrothermal carbon-coated electrospun PAN membranes which could absorb both cationic and anionic pollutants. The membranes had high removal efficiency in five successive cycles (Zhao et al. 2017b). Kim specifically developed Prussian blue embedded PAN membranes to remove radioactive Cs from the wastewater (Kim et al. 2018). 
Fig. 20.12 Desorption percentages of $\mathrm{Fe}$ (III), $\mathrm{Cu}$ (II), and $\mathrm{Cd}(\mathrm{II})$ ions upon regeneration of electrospun AOPAN/RC blend nanofiber membranes for $1-5$ cycles (Feng et al. 2018)

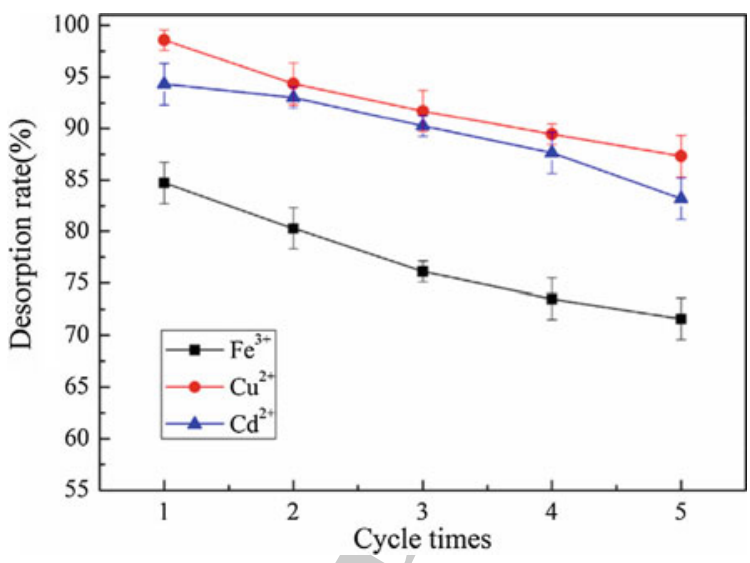

Alternately, a grafted phosphorylated PAN nanofiber membrane gained high adsorption performance towards $\mathrm{Pb}(\mathrm{II}), \mathrm{Cu}(\mathrm{II}), \mathrm{Ag}(\mathrm{I})$, and $\mathrm{Cd}(\mathrm{II})$; the removal efficiency remained high in four cycles (Zhao et al. 2015b).

Chen et al. synthesized adsorbents by intercalating ethylenediaminetetraacetic acid into layered double hydroxides; then they were embedded into the PAN spinning solution, and were encapsulated in the polymer matrix during electrospinning (Chen et al. 2018d). The composite membranes showed strong $\mathrm{Cu}$ (II) removal (Feng et al. 2018) (Fig. 20.12). Amidoxime groups could be imparted to PAN and blended with regenerated cellulose; the electrospun PAN membranes showed strong adsorption of $\mathrm{Fe}(\mathrm{III}), \mathrm{Cu}$ (II), and $\mathrm{Cd}(\mathrm{II})$. In five consecutive tests using the membranes, the adsorption and desorption rate of the heavy metal ions remained high. Cheaper polymers such as cellulose, PVA, or PVC were also used as base polymer for electrospun membranes, which were modified to acquire heavy metal adsorption ability (Wu et al. 2015; Islam et al. 2015; Cai et al. 2017). On the other hand, inorganic electrospun membranes, made of silica nanotubes or Hematite, were developed (Nalbandian et al. 2016; Wang et al. 2015). No requirement of modification, both natural membrane absorbents had strong adsorption capacity of heavy metals, and higher mechanical strength and chemical resistance than their polymer counterparts.

\subsection{Summary and Future Prospects}

The use of nanofibers for water and wastewater treatment is gaining fast ground for promising future use. This is primarily due to the many interesting and controllable properties and functionalities that can be designed for nanofiber membranes. The surge in nanofiber-related research for desalination, water, and wastewater treatment in the last decade provides evidence of its wide interest in various fields, may it be academe or industry. However, there are still a number of challenges that 
needed to be overcome before full commercialization can be realized especially for emerging applications. One of the biggest challenges that many are always curious about is the upscaling potential of the nanofiber fabrication. Though many new equipment have sprung providing glimpse of mass production potential, still if further modifications are needed after electrospinning, this could pose additional challenge. However, the future of electrospun membranes seems to be bright as advances in nanotechnologies in terms of precision and efficiency are making the electrospinning technique more viable with ease of operation. Also, newer nanomaterials and innovative surface modification methods are being realized, hence making it more attractive to apply to nanofibers with high surface area and porous structure that are essential for efficient membrane filtration process.

\section{References}

Ahmed FE, Lalia BS, Hashaikeh R (2015) A review on electrospinning for membrane fabrication: challenges and applications. Desalination 356:15-30. https://doi.org/10.1016/j.desal.2014.09. 033

Alcaraz-Espinoza JJ, Chavez-Guajardo AE, Medina-Llamas JC, Andrade CA, de Melo CP (2015) Hierarchical composite polyaniline-(electrospun polystyrene) fibers applied to heavy metal remediation. ACS Appl Mater Interfaces 7(13):7231-7240. https://doi.org/10.1021/acsami. $5 b 00326$

Aliabadi M, Irani M, Ismaeili J, Piri H, Parnian MJ (2013) Electrospun nanofiber membrane of $\mathrm{PEO} /$ Chitosan for the adsorption of nickel, cadmium, lead and copper ions from aqueous solution. Chem Eng J 220:237-243

An X, Liu Z, Hu Y (2018) Amphiphobic surface modification of electrospun nanofibrous membranes for anti-wetting performance in membrane distillation. Desalination 432:23-31. https://doi.org/10.1016/j.desal.2017.12.063

Arslan O, Aytac Z, Uyar T (2016) Superhydrophobic, hybrid, electrospun cellulose acetate nanofibrous mats for oil/water separation by tailored surface modification. ACS Appl Mater Interfaces 8(30):19747-19754. https://doi.org/10.1021/acsami.6b05429

Bae J, Baek I, Choi H (2016) Mechanically enhanced PES electrospun nanofiber membranes (ENMs) for microfiltration: The effects of ENM properties on membrane performance. Water Res 105:406-412

Bahmani P, Maleki A, Daraei H, Khamforoush M, Rezaee R, Gharibi F, Tkachev AG, Burakov AE, Agarwal S, Gupta VK (2017) High-flux ultrafiltration membrane based on electrospun polyacrylonitrile nanofibrous scaffolds for arsenate removal from aqueous solutions. J Colloid Interface Sci 506:564-571

Barakat NAM, Kanjwal MA, Sheikh FA, Kim HY (2009) Spider-net within the N6, PVA and PU electrospun nanofiber mats using salt addition: novel strategy in the electrospinning process. Polymer 50(18):4389-4396. https://doi.org/10.1016/j.polymer.2009.07.005

Bhardwaj N, Kundu SC (2010) Electrospinning: a fascinating fiber fabrication technique. Biotechnol Adv 28(3):325-347. https://doi.org/10.1016/j.biotechadv.2010.01.004

Bilad MR, Westbroek P, Vankelecom IFJ (2011) Assessment and optimization of electrospun nanofiber-membranes in a membrane bioreactor (MBR). J Membr Sci 380(1-2):181-191. https://doi.org/10.1016/j.memsci.2011.07.003

Bjorge D, Daels N, De Vrieze S, Dejans P, Van Camp T, Audenaert W, Hogie J, Westbroek P, De Clerck K, Van Hulle SWH (2009) Performance assessment of electrospun nanofibers for filter applications. Desalination 249(3):942-948. https://doi.org/10.1016/j.desal.2009.06.064 
Bjorge D, Daels N, De Vrieze S, Dejans P, Van Camp T, Audenaert W, Westbroek P, De Clerck K, Boeckaert C, Van Hulle SW (2010) Initial testing of electrospun nanofibre filters in water filtration applications. Water SA 36(1):151-156

Cai J, Lei M, Zhang Q, He J-R, Chen T, Liu S, Fu S-H, Li T-T, Liu G, Fei P (2017) Electrospun composite nanofiber mats of Cellulose@Organically modified montmorillonite for heavy metal ion removal: design, characterization, evaluation of absorption performance. Compos A Appl Sci Manuf 92:10-16. https://doi.org/10.1016/j.compositesa.2016.10.034

Chen M, Wu Y, Song W, Mo Y, Lin X, He Q, Guo B (2018a) Plasmonic nanoparticle-embedded poly(p-phenylene benzobisoxazole) nanofibrous composite films for solar steam generation. Nanoscale 10(13):6186-6193. https://doi.org/10.1039/c8nr01017j

Chen L, Wu F, Li Y, Wang Y, Si L, Lee KI, Fei B (2018b) Robust and elastic superhydrophobic breathable fibrous membrane with in situ grown hierarchical structures. J Membr Sci 547:9398. https://doi.org/10.1016/j.memsci.2017.10.023

Chen L, Li Y, Chen L, Li N, Dong C, Chen Q, Liu B, Ai Q, Si P, Feng J, Zhang L, Suhr J, Lou J, Ci L (2018c) A large-area free-standing graphene oxide multilayer membrane with high stability for nanofiltration applications. Chem Eng J 345:536-544. https://doi.org/10.1016/j.cej. 2018.03.136

Chen H, Lin J, Zhang N, Chen L, Zhong S, Wang Y, Zhang W, Ling Q (2018d) Preparation of MgAl-EDTA-LDH based electrospun nanofiber membrane and its adsorption properties of copper(II) from wastewater. J Hazard Mater 345:1-9. https://doi.org/10.1016/j.jhazmat.2017. 11.002

Cheng B, Li Z, Li Q, Ju J, Kang W, Naebe M (2017) Development of smart poly(vinylidene fluoride)-graft-poly(acrylic acid) tree-like nanofiber membrane for $\mathrm{pH}$-responsive oil/water separation. J Membr Sci 534:1-8. https://doi.org/10.1016/j.memsci.2017.03.053

Chitpong N, Husson SM (2017) Polyacid functionalized cellulose nanofiber membranes for removal of heavy metals from impaired waters. J Membr Sci 523:418-429

Chowdhury MR, Huang L, McCutcheon JR (2017) Thin film composite membranes for forward osmosis supported by commercial nanofiber nonwovens. Ind Eng Chem Res 56(4):1057-1063. https://doi.org/10.1021/acs.iecr.6b04256

Chronakis IS (2005) Novel nanocomposites and nanoceramics based on polymer nanofibers using electrospinning process - a review. J Mater Process Technol 167(2):283-293. https://doi.org/ 10.1016/j.jmatprotec.2005.06.053

De Vrieze S, Van Camp T, Nelvig A, Hagström B, Westbroek P, De Clerck K (2008) The effect of temperature and humidity on electrospinning. J Mater Sci 44(5):1357. https://doi.org/10.1007/ s10853-008-3010-6

Deng L, Ye H, Li X, Li P, Zhang J, Wang X, Zhu M, Hsiao BS (2018) Self-roughened omniphobic coatings on nanofibrous membrane for membrane distillation. Sep Purif Technol 206:14-25. https://doi.org/10.1016/j.seppur.2018.05.035

Ejaz Ahmed F, Lalia BS, Hilal N, Hashaikeh R (2014) Underwater superoleophobic cellulose/ electrospun PVDF-HFP membranes for efficient oil/water separation. Desalination 344:48-54. https://doi.org/10.1016/j.desal.2014.03.010

Fan Y, Chen S, Zhao H, Liu Y (2017) Distillation membrane constructed by $\mathrm{TiO}_{2}$ nanofiber followed by fluorination for excellent water desalination performance. Desalination 405:51-58. https://doi.org/10.1016/j.desal.2016.11.028

Feng Q, Wu D, Zhao Y, Wei A, Wei Q, Fong H (2018) Electrospun AOPAN/RC blend nanofiber membrane for efficient removal of heavy metal ions from water. J Hazard Mater 344:819-828. https://doi.org/10,1016/j.jhazmat.2017.11.035

Formo E, Lee E, Campbell D, Xia Y (2008) Functionalization of electrospun $\mathrm{TiO}_{2}$ nanofibers with Pt nanoparticles and nanowires for catalytic applications. Nano Lett 8(2):668-672. https://doi. org/10.1021/n1073163v

Gaikwad MS, Balomajumder C (2016) Capacitive deionization for desalination using nanostructured electrodes. Anal Lett 49(11):1641-1655. https://doi.org/10.1080/00032719.2015. 1118485 
Ghaffar A, Zhang L, Zhu X, Chen B (2018) Porous PVdF/GO nanofibrous membranes for selective separation and recycling of charged organic dyes from water. Environ Sci Technol 52 (7):4265-4274. https://doi.org/10.1021/acs.est.7b06081

Goh PS, Ismail AF, Hilal N (2016) Nano-enabled membranes technology: sustainable and revolutionary solutions for membrane desalination? Desalination 380:100-104. https://doi.org/ 10.1016/j.desal.2015.06.002

Gopakumar DA, Pasquini D, Henrique MA, de Morais LC, Grohens Y, Thomas S (2017) Meldrum's acid modified cellulose nanofiber-based polyvinylidene fluoride microfiltration membrane for dye water treatment and nanoparticle removal. ACS Sustain Chem Eng 5 (2):2026-2033. https://doi.org/10.1021/acssuschemeng.6b02952

Habiba U, Siddique TA, Talebian S, Lee JJL, Salleh A, Ang BC, Afifi AM (2017a) Effect of deacetylation on property of electrospun chitosan/PVA nanofibrous membrane and removal of methyl orange, Fe(III) and Cr(VI) ions. Carbohydr Polym 177:32-39. https://doi.org/10.1016/j. carbpol.2017.08.115

Habiba U, Afifi AM, Salleh A, Ang BC (2017b) Chitosan/(polyvinyl alcohol)/zeolite electrospun composite nanofibrous membrane for adsorption of $\mathrm{Cr}^{6+}, \mathrm{Fe}^{3+}$ and $\mathrm{Ni}^{2}$. J Hazard Mater 322( $\mathrm{Pt}$ A):182-194. https://doi.org/10.1016/j.jhazmat.2016.06.028

Hadi Najafabadi H, Irani M, Roshanfekr Rad L, Heydari Haratameh A, Haririan I (2015) Removal of $\mathrm{Cu}^{2+}, \mathrm{Pb}^{2+}$ and $\mathrm{Cr}^{6+}$ from aqueous solutions using a chitosan/graphene oxide composite nanofibrous adsorbent. RSC Adv 5(21):16532-16539. https://doi.org/10.1039/c5ra01500f

Haghi AK, Akbari M (2007) Trends in electrospinning of natural nanofibers. Physica Status Solidi 204(6):1830-1834. https://doi.org/10.1002/pssa.200675301

Haider S, Haider A, Ahmad A, Khan SU-D, Almasry WA, Sarfarz M (2015) Electrospun nanofibers affinity membranes for water hazards remediation. Nanotechnol Res J 8(4):511

Han MJ, Baroña GNB, Jung B (2011) Effect of surface charge on hydrophilically modified poly (vinylidene fluoride) membrane for microfiltration. Desalination 270(1-3):76-83

Horzum N, Demir MM, Nairat M, Shahwan T (2013) Chitosan fiber-supported zero-valent iron nanoparticles as a novel sorbent for sequestration of inorganic arsenic. RSC Adv 3(21):7828. https://doi.org/10.1039/c3ra23454a

Hosseini SA, Vossoughi M, Mahmoodi NM, Sadrzadeh M (2018) Efficient dye removal from aqueous solution by high-performance electrospun nanofibrous membranes through incorporation of $\mathrm{SiO}_{2}$ nanoparticles. J Clean Prod 183:1197-1206. https://doi.org/10.1016/j.jclepro. 2018.02.168

Hou D, Wang Z, Wang K, Wang J, Lin S (2018) Composite membrane with electrospun multiscale-textured surface for robust oil-fouling resistance in membrane distillation. J Membr Sci 546:179-187. https://doi.org/10.1016/j.memsci.2017.10.017

Huang Z-M, Zhang YZ, Kotaki M, Ramakrishna S (2003) A review on polymer nanofibers by electrospinning and their applications in nanocomposites. Composites Sci Technol 63 (15):2223-2253. https://doi.org/10.1016/S0266-3538(03)00178-7

Huang Y, Miao YE, Liu T (2014) Electrospun fibrous membranes for efficient heavy metal removal. J Appl Polymer Sci 131(19)

Huang Y-X, Wang Z, Hou D, Lin S (2017a) Coaxially electrospun super-amphiphobic silica-based membrane for anti-surfactant-wetting membrane distillation. J Membr Sci 531:122-128. https://doi.org/10.1016/j.memsci.2017.02.044

Huang YX, Wang Z, Jin J, Lin S (2017b) Novel janus membrane for membrane distillation with simultaneous fouling and wetting resistance. Environ Sci Technol 51(22):13304-13310. https://doi.org/10,1021/acs.est.7b02848

Huang M, Tu H, Chen J, Liu R, Liang Z, Jiang L, Shi X, Du Y, Deng H (2018) Chitosan-rectorite nanospheres embedded aminated polyacrylonitrile nanofibers via shoulder-to-shoulder electrospinning and electrospraying for enhanced heavy metal removal. Appl Surf Sci 437:294303. https://doi.org/10.1016/j.apsusc.2017.12.150

Islam MS, Rahaman MS, Yeum JH (2015) Phosphine-functionalized electrospun poly(vinyl alcohol)/silica nanofibers as highly effective adsorbent for removal of aqueous manganese and nickel ions. Colloids Surf A 484:9-18. https://doi.org/10.1016/j.colsurfa.2015.07.023 
Islam MS, McCutcheon JR, Rahaman MS (2017) A high flux polyvinyl acetate-coated electrospun nylon $6 / \mathrm{SiO}_{2}$ composite microfiltration membrane for the separation of oil-in-water emulsion with improved antifouling performance. J Membr Sci 537:297-309. https://doi.org/10.1016/j. memsci.2017.05.019

Jang W, Yun J, Jeon K, Byun H (2015) PVdF/graphene oxide hybrid membranes via electrospinning for water treatment applications. RSC Adv 5(58):46711-46717

Jiang J, Carlson MA, Teusink MJ, Wang H, MacEwan MR, Xie J (2015) Expanding two-dimensional electrospun nanofiber membranes in the third dimension by a modified gas-foaming technique. ACS Biomater Sci Eng 1(10):991-1001. https://doi.org/10.1021/ acsbiomaterials. 5 b00238

Jiang S, Chen Y, Duan G, Mei C, Greiner A, Agarwal S (2018) Electrospun nanofiber reinforced composites: a review. Polymer Chem 9(20):2685-2720. https://doi.org/10.1039/C8PY00378E

Jingwei X, Xiaoran L, Younan X (2008) Putting electrospun nanofibers to work for biomedical research. Macromol Rapid Commun 29(22):1775-1792. https://doi.org/doi:10.1002/marc. 200800381

Kabeel AE, El-Agouz SA (2011) Review of researches and developments on solar stills. Desalination 276(1):1-12. https://doi.org/10.1016/j.desal.2011.03.042

Ki CS, Baek DH, Gang KD, Lee KH, Um IC, Park YH (2005) Characterization of gelatin nanofiber prepared from gelatin-formic acid solution. Polymer 46(14):5094-5102. https://doi. org/10.1016/j.polymer.2005.04.040

Kim G, Kim W (2007) Highly porous 3D nanofiber scaffold using an electrospinning technique. J Biomed Mater Res B Appl Biomater 81B(1):104-110. https://doi.org/doi:10.1002/jbm.b. 30642

Kim JI, Kim CS (2018) Harnessing nanotopography of PCL/collagen nanocomposite membrane and changes in cell morphology coordinated with wound healing activity. Mater Sci Eng C 91:824-837. https://doi.org/10.1016/j.msec.2018.06.021

Kim B, Park H, Lee S-H, Sigmund WM (2005) Poly(acrylic acid) nanofibers by electrospinning. Mater Lett 59(7):829-832. https://doi.org/10.1016/j.matlet.2004.11.032

Kim JJ, Yoon H, Hong J, Lee T, Wilf M (2013) Evaluation of new compact pretreatment system for high turbidity seawater: fiber filter and ultrafiltration. Desalination 313:28-35

Kim JI, Hwang TI, Aguilar LE, Park CH, Kim CS (2016) A controlled design of aligned and random nanofibers for $3 \mathrm{D}$ bi-functionalized nerve conduits fabricated via a novel electrospinning set-up. Sci Rep 6:23761. https://doi.org/10.1038/srep23761

Kim H, Kim M, Lee W, Kim S (2018) Rapid removal of radioactive cesium by polyacrylonitrile nanofibers containing Prussian blue. J Hazard Mater 347:106-113. https://doi.org/10.1016/j. jhazmat.2017.12.050

Le NL, Nunes SP (2016) Materials and membrane technologies for water and energy sustainability. Sustain Mater Technol 7:1-28. https://doi.org/10.1016/j.susmat.2016.02.001

Lee J, Boo C, Ryu W-H, Taylor AD, Elimelech M (2016) Development of omniphobic desalination membranes using a charged electrospun nanofiber scaffold. ACS Appl Mater Interfaces 8(17):11154-11161. https://doi.org/10.1021/acsami.6b02419

Lefevre E, Bossa N, Wiesner MR, Gunsch CK (2016) A review of the environmental implications of in situ remediation by nanoscale zero valent iron (nZVI): behavior, transport and impacts on microbial communities. Sci Total Environ 565:889-901

Li D, Xia Y (2004) Direct fabrication of composite and ceramic hollow nanofibers by electrospinning. Nano Lett 4(5):933-938. https://doi.org/10.1021/nl049590f

Li D, Wang Y, Xia Y (2003) Electrospinning of polymeric and ceramic nanofibers as uniaxially aligned arrays. Nano Lett 3(8):1167-1171. https://doi.org/10.1021/n10344256

Li D, McCann J, Xia Y (2005) Use of electrospinning to directly fabricate hollow nanofibers with functionalized inner and outer surfaces. Small 1(1):83-86. https://doi.org/10.1002/smll. 200400056

Li X, Wang M, Wang C, Cheng C, Wang X (2014) Facile immobilization of ag nanocluster on nanofibrous membrane for oil/water separation. ACS Appl Mater Interfaces 6(17):1527215282. https://doi.org/10.1021/am503721k 
Li JJ, Zhou YN, Luo ZH (2015) Smart fiber membrane for pH-induced oil/water separation. ACS Appl Mater Interfaces 7(35):19643-19650. https://doi.org/10.1021/acsami.5b04146

$\mathrm{Li}$ Y, Zhao $\mathrm{H}$, Yang M (2017a) $\mathrm{TiO}_{2}$ nanoparticles supported on PMMA nanofibers for photocatalytic degradation of methyl orange. J Colloid Interface Sci 508:500-507. https://doi. org/10.1016/j.jcis.2017.08.076

Li W, Li T, Li G, An L, Li F, Zhang Z (2017b) Electrospun H4SiW12O40/cellulose acetate composite nanofibrous membrane for photocatalytic degradation of tetracycline and methyl orange with different mechanism. Carbohydr Polym 168:153-162. https://doi.org/10.1016/j. carbpol.2017.03.079

Li L, Wang F, Lv Y, Liu J, Zhang D, Shao Z (2018) Halloysite nanotubes and $\mathrm{Fe}_{3} \mathrm{O}_{4}$ nanoparticles enhanced adsorption removal of heavy metal using electrospun membranes. Appl Clay Sci 161:225-234. https://doi.org/10.1016/j.clay.2018.04.002

Lian G, Zhang X, Si H, Wang J, Cui D, Wang Q (2013) Boron nitride ultrathin fibrous nanonets: one-step synthesis and applications for ultrafast adsorption for water treatment and selective filtration of nanoparticles. ACS Appl Mater Interfaces 5(24):12773-12778. https://doi.org/10. $1021 / \mathrm{am} 403789 \mathrm{c}$

Liao Y, Wang R, Fane AG (2013) Engineering superhydrophobic surface on poly(vinylidene fluoride) nanofiber membranes for direct contact membrane distillation. J Membr Sci 440:7787. https://doi.org/10.1016/j.memsci.2013.04.006

Lin KA, Lin JT, Lu XY, Hung C, Lin YF (2017) Electrospun magnetic cobalt-embedded carbon nanofiber as a heterogeneous catalyst for activation of oxone for degradation of Amaranth dye. J Colloid Interface Sci 505:728-735. https://doi.org/10.1016/j.jcis.2017.06.057

Liu A, Liu J, Pan B, W-x Zhang (2014a) Formation of lepidocrocite $(\gamma$-FeOOH) from oxidation of nanoscale zero-valent iron (nZVI) in oxygenated water. RSC Adv 4(101):57377-57382

Liu C, Li X, Ma B, Qin A, He C (2014b) Removal of water contaminants by nanoscale zero-valent iron immobilized in PAN-based oxidized membrane. Appl Surf Sci 321:158-165. https://doi. org/10.1016/j.apsusc.2014.09.202

Liu Y, Ma J, Lu T, Pan L (2016a) Electrospun carbon nanofibers reinforced 3D porous carbon polyhedra network derived from metal-organic frameworks for capacitive deionization. Sci Rep 6:32784. https://doi.org/10.1038/srep32784

Liu Z, Wang H, Wang E, Zhang X, Yuan R, Zhu Y (2016b) Superhydrophobic poly(vinylidene fluoride) membranes with controllable structure and tunable wettability prepared by one-step electrospinning. Polymer 82:105-113. https://doi.org/10.1016/j.polymer.2015.11.045

Luana P, Andrea C, Cagri T, Dario P (2013) Industrial upscaling of electrospinning and applications of polymer nanofibers: a review. Macromol Mater Eng 298(5):504-520. https:// doi.org/doi:10.1002/mame.201200290

Ma Q, Wang J, Dong X, Yu W, Liu G, Xu J (2012) Electrospinning preparation and properties of magnetic-photoluminescent bifunctional coaxial nanofibers. J Mater Chem 22(29):1443814442. https://doi.org/10.1039/C2JM32043F

Matabola KP, Moutloali RM (2013) The influence of electrospinning parameters on the morphology and diameter of poly(vinyledene fluoride) nanofibers - effect of sodium chloride. J Mater Sci 48(16):5475-5482. https://doi.org/10.1007/s10853-013-7341-6

Mino Y, Shinto H, Sakai S, Matsuyama H (2017) Effect of internal mass in the lattice Boltzmann simulation of moving solid bodies by the smoothed-profile method. Phys Rev E 95(4). https:// doi.org/10.1103/physreve.95.043309

Moradi G, Rajabi L, Dabirian F, Zinadini S (2018) Biofouling alleviation and flux enhancement of electrospun PAN microfiltration membranes by embedding of para-aminobenzoate alumoxane nanoparticles. J Appl Polymer Sci 135(7). https://doi.org/10.1002/app.45738

Moradi G, Zinadini S, Rajabi L, Dadari S (2018b) Fabrication of high flux and antifouling mixed matrix fumarate-alumoxane/PAN membranes via electrospinning for application in membrane bioreactors. Appl Surf Sci 427:830-842. https://doi.org/10.1016/j.apsusc.2017.09.039

Nalbandian MJ, Zhang M, Sanchez J, Choa YH, Nam J, Cwiertny DM, Myung NV (2016) Synthesis and optimization of $\mathrm{Fe}_{2} \mathrm{O}_{3}$ nanofibers for chromate adsorption from contaminated water sources. Chemosphere 144:975-981. https://doi.org/10.1016/j.chemosphere.2015.08.056 
Obaid M, Barakat NAM, Fadali OA, Motlak M, Almajid AA, Khalil KA (2015) Effective and reusable oil/water separation membranes based on modified polysulfone electrospun nanofiber mats. Chem Eng J 259:449-456. https://doi.org/10.1016/j.cej.2014.07.095

Oren Y (2008) Capacitive deionization (CDI) for desalination and water treatment - past, present and future (a review). Desalination 228(1):10-29. https://doi.org/10.1016/j.desal.2007.08.005

Park JJ, Hyun WJ, Mun SC, Park YT, Park OO (2015) Highly stretchable and wearable graphene strain sensors with controllable sensitivity for human motion monitoring. ACS Appl Mater Interfaces 7(11):6317-6324. https://doi.org/10.1021/acsami.5b00695

Park MJ, Gonzales RR, Abdel-Wahab A, Phuntsho S, Shon HK (2018) Hydrophilic polyvinyl alcohol coating on hydrophobic electrospun nanofiber membrane for high performance thin film composite forward osmosis membrane. Desalination 426:50-59. https://doi.org/10.1016/j. desal.2017.10.042

Phuntsho S, Shon HK, Hong S, Lee S, Vigneswaran S (2011) A novel low energy fertilizer driven forward osmosis desalination for direct fertigation: evaluating the performance of fertilizer draw solutions. J Membr Sci 375(1):172-181. https://doi.org/10.1016/j.memsci.2011.03.038

Porada S, Weinstein L, Dash R, van der Wal A, Bryjak M, Gogotsi Y, Biesheuvel PM (2012) Water desalination using capacitive deionization with microporous carbon electrodes. ACS Appl Mater Interfaces 4(3):1194-1199. https://doi.org/10.1021/am201683j

Qing W, Shi X, Deng Y, Zhang W, Wang J, Tang CY (2017) Robust superhydrophobicsuperoleophilic polytetrafluoroethylene nanofibrous membrane for oil/water separation. J Membr Sci 540:354-361. https://doi.org/10.1016/j.memsci.2017.06.060

Ray SS, Chen S-S, Nguyen NC, Hsu H-T, Nguyen HT, Chang C-T (2017) Poly(vinyl alcohol) incorporated with surfactant based electrospun nanofibrous layer onto polypropylene mat for improved desalination by using membrane distillation. Desalination 414:18-27. https://doi.org/ 10.1016/j.desal.2017.03.032

Ren L-F, Xia F, Chen V, Shao J, Chen R, He Y (2017a) TiO2-FTCS modified superhydrophobic PVDF electrospun nanofibrous membrane for desalination by direct contact membrane distillation. Desalination 423:1-11. https://doi.org/10.1016/j.desal.2017.09.004

Ren J, Woo YC, Yao M, Tijing LD, Shon HK (2017b) Enhancement of nanoscale zero-valent iron immobilization onto electrospun polymeric nanofiber mats for groundwater remediation. Process Saf Environ Prot 112:200-208

Ren B, Shen W, Li L, Wu S, Wang W (2018) 3D CoFe $\mathrm{O}_{4}$ nanorod/flower-like $\mathrm{MoS}_{2}$ nanosheet heterojunctions as recyclable visible light-driven photocatalysts for the degradation of organic dyes. Appl Surf Sci 447:711-723. https://doi.org/10.1016/j.apsusc.2018.04.064

Saepurahman Singaravel GP, Hashaikeh R (2015) Fabrication of electrospun LTL zeolite fibers and their application for dye removal. J Mater Sci 51(2):1133-1141. https://doi.org/10.1007/ s10853-015-9444-8

Satilmis B, Uyar T (2018) Amine modified electrospun PIM-1 ultrafine fibers for an efficient removal of methyl orange from an aqueous system. Appl Surf Sci 453:220-229. https://doi.org/ 10.1016/j.apsusc.2018.05.069

Schiwy A, Maes HM, Koske D, Flecken M, Schmidt KR, Schell H, Tiehm A, Kamptner A, Thümmler S, Stanjek H (2016) The ecotoxic potential of a new zero-valent iron nanomaterial, designed for the elimination of halogenated pollutants, and its effect on reductive dechlorinating microbial communities. Environ Pollut 216:419-427

Shannon MA, Bohn PW, Elimelech M, Georgiadis JG, Mariñas BJ, Mayes AM (2008) Science and technology for water purification in the coming decades. Nature 452:301. https://doi.org/ 10.1038/nature06599

Shariful MI, Sharif SB, Lee JJL, Habiba U, Ang BC, Amalina MA (2017) Adsorption of divalent heavy metal ion by mesoporous-high surface area chitosan/poly (ethylene oxide) nanofibrous membrane. Carbohydr Polym 157:57-64. https://doi.org/10.1016/j.carbpol.2016.09.063

Shenvi SS, Isloor AM, Ismail AF (2015) A review on RO membrane technology: developments and challenges. Desalination 368:10-26. https://doi.org/10.1016/j.desal.2014.12.042

Shi J, Wu T, Teng K, Wang W, Shan M, Xu Z, Lv H, Deng H (2016) Simultaneous electrospinning and spraying toward branch-like nanofibrous membranes functionalised with 
carboxylated MWCNTs for dye removal. Mater Lett 166:26-29. https://doi.org/10.1016/j. matlet.2015.12.024

Sill TJ, von Recum HA (2008) Electrospinning: applications in drug delivery and tissue engineering. Biomaterials 29(13):1989-2006. https://doi.org/10.1016/j.biomaterials.2008.01. 011

Singh N, Prakash J, Misra M, Sharma A, Gupta RK (2017) Dual functional Ta-doped electrospun $\mathrm{TiO}_{2}$ nanofibers with enhanced photocatalysis and SERS detection for organic compounds. ACS Appl Mater Interfaces 9(34):28495-28507. https://doi.org/10.1021/acsami.7b07571

Son M, Bae J, Park H, Choi H (2018) Continuous thermal-rolling of electrospun nanofiber for polyamide layer deposition and its detection by engineered osmosis. Polymer 145:281-285. https://doi.org/10.1016/j.polymer.2018.04.014

Su C, Lu C, Cao H, Gao F, Chang J, Li Y, He C (2017) Fabrication of a novel nanofibers-covered hollow fiber membrane via continuous electrospinning with non-rotational collectors. Mater Lett 204:8-11. https://doi.org/10.1016/j.matlet.2017.05.134

Tai MH, Gao P, Tan BY, Sun DD, Leckie JO (2014) Highly efficient and flexible electrospun carbon-silica nanofibrous membrane for ultrafast gravity-driven oil-water separation. ACS Appl Mater Interfaces 6(12):9393-9401. https://doi.org/10.1021/am501758c

Talwar S, Krishnan AS, Hinestroza JP, Pourdeyhimi B, Khan SA (2010) Electrospun nanofibers with associative polymer-surfactant systems. Macromolecules 43(18):7650-7656. https://doi. org/10.1021/ma1013447

Tao J, Shivkumar S (2007) Molecular weight dependent structural regimes during the electrospinning of PVA. Mater Lett 61(11):2325-2328. https://doi.org/10.1016/j.matlet.2006. 09.004

Teo WE, Ramakrishna S (2006) A review on electrospinning design and nanofibre assemblies. Nanotechnology 17(14):R89

Tian M, Wang Y-N, Wang R, Fane AG (2017) Synthesis and characterization of thin film nanocomposite forward osmosis membranes supported by silica nanoparticle incorporated nanofibrous substrate. Desalination 401:142-150. https://doi.org/10.1016/j.desal.2016.04.003

Tian H, Liang Y, Zhu T, Zeng X, Sun Y (2018) Surfactant-enhanced PEG-4000-NZVI for remediating trichloroethylene-contaminated soil. Chemosphere 195:585-593

Tijing LD, Ruelo MTG, Amarjargal A, Pant HR, Park C-H, Kim DW, Kim CS (2012a) Antibacterial and superhydrophilic electrospun polyurethane nanocomposite fibers containing tourmaline nanoparticles. Chem Eng J 197:41-48. https://doi.org/10.1016/j.cej.2012.05.005

Tijing LD, Ruelo MTG, Amarjargal A, Pant HR, Park C-H, Kim CS (2012b) One-step fabrication of antibacterial (silver nanoparticles/poly(ethylene oxide)) - polyurethane bicomponent hybrid nanofibrous mat by dual-spinneret electrospinning. Mater Chem Phys 134(2):557-561. https:// doi.org/10.1016/j.matchemphys.2012.03.037

Tijing LD, Choi J-S, Lee S, Kim S-H, Shon HK (2014a) Recent progress of membrane distillation using electrospun nanofibrous membrane. J Membr Sci 453:435-462. https://doi.org/10.1016/j. memsci.2013.11.022

Tijing LD, Woo YC, Johir MAH, Choi J-S, Shon HK (2014b) A novel dual-layer bicomponent electrospun nanofibrous membrane for desalination by direct contact membrane distillation. Chem Eng J 256:155-159. https://doi.org/10.1016/j.cej.2014.06.076

Tijing LD, Woo YC, Choi J-S, Lee S, Kim S-H, Shon HK (2015) Fouling and its control in membrane distillation - a review. J Membr Sci 475:215-244. https://doi.org/10.1016/j.memsci. 2014.09.042

Tijing LD, Woo YC, Shim W-G, He T, Choi J-S, Kim S-H, Shon HK (2016) Superhydrophobic nanofiber membrane containing carbon nanotubes for high-performance direct contact membrane distillation. J Membr Sci 502:158-170. https://doi.org/10.1016/j.memsci.2015.12. 014

Tijing LD, Woo YC, Yao M, Ren J, Shon HK (2017) 1.16 Electrospinning for membrane fabrication: strategies and applications. In: Drioli E, Giorno L, Fontananova E (eds) Comprehensive membrane science and engineering, 2nd edn. Elsevier, Oxford, pp 418-444. https://doi.org/10.1016/B978-0-12-409547-2.12262-0 
Tosco T, Papini MP, Viggi CC, Sethi R (2014) Nanoscale zerovalent iron particles for groundwater remediation: a review. J Clean Prod 77:10-21

Truex M, Johnson C, Macbeth T, Becker D, Lynch K, Giaudrone D, Frantz A, Lee H (2017) Performance assessment of pump-and-treat systems. Groundwater Monitor Remed 37(3): $28-44$

Tu H, Huang M, Yi Y, Li Z, Zhan Y, Chen J, Wu Y, Shi X, Deng H, Du Y (2017) Chitosan-rectorite nanospheres immobilized on polystyrene fibrous mats via alternate electrospinning/electrospraying techniques for copper ions adsorption. Appl Surf Sci 426:545-553. https://doi.org/10.1016/j.apsusc.2017.07.159

Varanasi S, Low Z-X, Batchelor W (2015) Cellulose nanofibre composite membranesbiodegradable and recyclable UF membranes. Chem Eng J 265:138-146

Vaselbehagh M, Karkhanechi H, Takagi R, Matsuyama H (2017) Biofouling phenomena on anion exchange membranes under the reverse electrodialysis process. J Membr Sci 530:232-239. https://doi.org/10.1016/j.memsci.2017.02.036

Wang P (2018) Emerging investigator series: the rise of nano-enabled photothermal materials for water evaporation and clean water production by sunlight. Environ Sci Nano 5(5):1078-1089. https://doi.org/10.1039/c8en00156a

Wang X, Ding B, Yu J, Yang J (2011) Large-scale fabrication of two-dimensional spider-web-like gelatin nano-nets via electro-netting. Colloids Surf B 86(2):345-352. https://doi.org/10.1016/j. colsurfb.2011.04.018

Wang P, Du M, Zhu H, Bao S, Yang T, Zou M (2015) Structure regulation of silica nanotubes and their adsorption behaviors for heavy metal ions: $\mathrm{pH}$ effect, kinetics, isotherms and mechanism. J Hazard Mater 286:533-544. https://doi.org/10.1016/j.jhazmat.2014.12.034

Wang G, Qian B, Wang Y, Dong Q, Zhan F, Qiu J (2016) Electrospun porous hierarchical carbon nanofibers with tailored structures for supercapacitors and capacitive deionization. New $\mathbf{J}$ Chem 40(4):3786-3792. https://doi.org/10.1039/C5NJ02963E

Wang X, Ma H, Chu B, Hsiao BS (2017a) Thin-film nanofibrous composite reverse osmosis membranes for desalination. Desalination 420:91-98. https://doi.org/10.1016/j.desal.2017.06. 029

Wang Z, Crandall C, Prautzsch VL, Sahadevan R, Menkhaus TJ, Fong H (2017b) Electrospun regenerated cellulose nanofiber membranes surface-grafted with water-insoluble poly (HEMA) or water-soluble poly (AAS) chains via the ATRP method for ultrafiltration of water. ACS Appl Mater Interfaces 9(4):4272-4278

Wang X, Dou L, Yang L, Yu J, Ding B (2017c) Hierarchical structured $\mathrm{MnO}_{2} @ \mathrm{SiO}_{2}$ nanofibrous membranes with superb flexibility and enhanced catalytic performance. J Hazard Mater 324(Pt B):203-212. https://doi.org/10.1016/j.jhazmat.2016.10.050

Wang J, La Hou, Yan K, Zhang L, Yu QJ (2018) Polydopamine nanocluster decorated electrospun nanofibrous membrane for separation of oil/water emulsions. J Membr Sci 547:156-162. https://doi.org/10.1016/j.memsci.2017.10.028

Woo YC, Tijing LD, Shim W-G, Choi J-S, Kim S-H, He T, Drioli E, Shon HK (2016) Water desalination using graphene-enhanced electrospun nanofiber membrane via air gap membrane distillation. J Membr Sci 520:99-110. https://doi.org/10.1016/j.memsci.2016.07.049

Woo YC, Chen Y, Tijing LD, Phuntsho S, He T, Choi J-S, Kim S-H, Kyong Shon H (2017a) CF4 plasma-modified omniphobic electrospun nanofiber membrane for produced water brine treatment by membrane distillation. J Membr Sci 529:234-242. https://doi.org/10.1016/j. memsci.2017.01.063

Woo YC, Chen Y, Tijing LD, Phuntsho S, He T, Choi J-S, Kim S-H, Shon HK (2017b) CF4 plasma-modified omniphobic electrospun nanofiber membrane for produced water brine treatment by membrane distillation. J Membr Sci 529:234-242

Wu S-H, Qin X-H (2013) Uniaxially aligned polyacrylonitrile nanofiber yarns prepared by a novel modified electrospinning method. Mater Lett 106:204-207. https://doi.org/10.1016/j.matlet. 2013.05.010

Wu Z-Y, Li C, Liang H-W, Zhang Y-N, Wang X, Chen J-F, Yu S-H (2014) Carbon nanofiber aerogels for emergent cleanup of oil spillage and chemical leakage under harsh conditions. Sci 
Rep 4:4079. https://doi.org/10.1038/srep04079. https://www.nature.com/articles/ srep04079\#supplementary-information

Wu C, Wang H, Wei Z, Li C, Luo Z (2015) Polydopamine-mediated surface functionalization of electrospun nanofibrous membranes: preparation, characterization and their adsorption properties towards heavy metal ions. Appl Surf Sci 346:207-215. https://doi.org/10.1016/j. apsusc.2015.04.001

Xiao S, Shen M, Ma H, Guo R, Zhu M, Wang S, Shi X (2010) Fabrication of water-stable electrospun polyacrylic acid-based nanofibrous mats for removal of copper (II) ions in aqueous solution. J Appl Polym Sci 116(4):2409-2417

Xing R, Wang W, Jiao T, Ma K, Zhang Q, Hong W, Qiu H, Zhou J, Zhang L, Peng Q (2017) Bioinspired polydopamine sheathed nanofibers containing carboxylate graphene oxide nanosheet for high-efficient dyes scavenger. ACS Sustain Chem Eng 5(6):4948-4956. https://doi.org/10.1021/acssuschemeng.7b00343

Xu G-R, Wang J-N, Li C-J (2013) Strategies for improving the performance of the polyamide thin film composite (PA-TFC) reverse osmosis (RO) membranes: surface modifications and nanoparticles incorporations. Desalination 328:83-100. https://doi.org/10.1016/j.desal.2013. 08.022

Xu W, Chen Q, Ge Q (2017) Recent advances in forward osmosis (FO) membrane: chemical modifications on membranes for FO processes. Desalination 419:101-116. https://doi.org/10. 1016/j.desal.2017.06.007

Xue J, Xie J, Liu W, Xia Y (2017) Electrospun nanofibers: new concepts, materials, and applications. Acc Chem Res 50(8):1976-1987. https://doi.org/10.1021/acs.accounts.7b00218

Xue W, Huang D, Zeng G, Wan J, Zhang C, Xu R, Cheng M, Deng R (2018) Nanoscale zero-valent iron coated with rhamnolipid as an effective stabilizer for immobilization of $\mathrm{Cd}$ and $\mathrm{Pb}$ in river sediments. J Hazard Mater 341:381-389

Yan J, Huang Y, Miao YE, Tjiu WW, Liu T (2015) Polydopamine-coated electrospun poly(vinyl alcohol)/poly(acrylic acid) membranes as efficient dye adsorbent with good recyclability. J Hazard Mater 283:730-739. https://doi.org/10.1016/j.jhazmat.2014.10.040

Yang J, Wang X, Zhu M, Liu H, Ma J/2014) Investigation of PAA/PVDF-NZVI hybrids for metronidazole removal: synthesis, characterization, and reactivity characteristics. J Hazard Mater 264:269-277

Yang Z, Lu J, Ye W, Yu C, Chang Y (2017) Preparation of Pt/TiO 2 hollow nanofibers with highly visible light photocatalytic activity. Appl Surf Sci 392:472-480. https://doi.org/10.1016/j. apsusc.2016.09.065

Yao M, Woo Y, Tijing L, Cesarini C, Shon H (2017) Improving nanofiber membrane characteristics and membrane distillation performance of heat-pressed membranes via annealing post-treatment. Appl Sci 7(1):78

Yao M, Woo YC, Tijing LD, Choi J-S, Shon HK (2018) Effects of volatile organic compounds on water recovery from produced water via vacuum membrane distillation. Desalination 440:146155. https://doi.org/10.1016/j,desal.2017.11.012

Yasin AS, Obaid M, Mohamed IA, Yousef A, Barakat NAM (2017) ZrO2 nanofibers/activated carbon composite as a novel and effective electrode material for the enhancement of capacitive deionization performance. RSC Adv 7(8):4616-4626. https://doi.org/10.1039/c6ra26039j

Yasin AS, Mohamed IMA, Park CH, Kim CS (2018) Design of novel electrode for capacitive deionization using electrospun composite titania/zirconia nanofibers doped-activated carbon. Mater Lett 213:62-66. https://doi.org/10.1016/j.matlet.2017.11.001

Yoon K, Hsiao BS, Chu B (2009) High flux nanofiltration membranes based on interfacially polymerized polyamide barrier layer on polyacrylonitrile nanofibrous scaffolds. J Membr Sci 326(2):484-492. https://doi.org/10.1016/j.memsci.2008.10.023

Yu Y, Ma R, Yan S, Fang J (2018) Preparation of multi-layer nylon-6 nanofibrous membranes by electrospinning and hot pressing methods for dye filtration. RSC Adv 8(22):12173-12178. https://doi.org/10.1039/c8ra01442f 
Zhan Y, Wan X, He S, Yang Q, He Y (2018) Design of durable and efficient poly(arylene ether nitrile)/bioinspired polydopamine coated graphene oxide nanofibrous composite membrane for anionic dyes separation. Chem Eng J 333:132-145. https://doi.org/10.1016/j.cej.2017.09.147

Zhang L, Aboagye A, Kelkar A, Lai C, Fong H (2014) A review: carbon nanofibers from electrospun polyacrylonitrile and their applications. J Mater Sci 49(2):463-480. https://doi.org/ 10.1007/s10853-013-7705-y

Zhang J, Pan X, Xue Q, He D, Zhu L, Guo Q (2017) Antifouling hydrolyzed polyacrylonitrile/ graphene oxide membrane with spindle-knotted structure for highly effective separation of oil-water emulsion. J Membr Sci 532:38-46. https://doi.org/10.1016/j.memsci.2017.03.004

Zhang C, Han Y, Zhang T, Wang H, Wen G (2018) Designed fabrication of hierarchical porous carbon nanotubes/graphene/carbon nanofibers composites with enhanced capacitive desalination properties. J Mater Sci 53(13):9521-9532. https://doi.org/10.1007/s10853-018-2240-5

Zhao R, Wang Y, Li X, Sun B, Wang C (2015a) Synthesis of beta-cyclodextrin-based electrospun nanofiber membranes for highly efficient adsorption and separation of methylene blue. ACS Appl Mater Interfaces 7(48):26649-26657. https://doi.org/10.1021/acsami.5b08403

Zhao R, Li X, Sun B, Shen M, Tan X, Ding Y, Jiang Z, Wang C (2015b) Preparation of phosphorylated polyacrylonitrile-based nanofiber mat and its application for heavy metal ion removal. Chem Eng J 268:290-299. https://doi.org/10.1016/j.cej.2015.01.061

Zhao C, Lv X, Li J, Xie T, Qi Y, Chen W (2017a) Manganese oxide nanoparticles decorated ordered mesoporous carbon electrode for capacitive deionization of brackish water. J Electrochem Soc 164(13):E505-E511. https://doi.org/10.1149/2.0141714jes

Zhao R, Li X, Sun B, Ji H, Wang C (2017b) Diethylenetriamine-assisted synthesis of amino-rich hydrothermal carbon-coated electrospun polyacrylonitrile fiber adsorbents for the removal of $\mathrm{Cr}(\mathrm{VI})$ and 2,4-dichlorophenoxyacetic acid. J Colloid Interface Sci 487:297-309. https://doi. org/10.1016/j.jcis.2016.10.057

Zhou Z, Wu X-F (2015) Electrospinning superhydrophobic-superoleophilic fibrous PVDF membranes for high-efficiency water-oil separation, Mater Lett 160:423-427. https://doi.org/ 10.1016/j.matlet.2015.08.003

Zhou L, Tan Y, Wang J, Xu W, Yuan Y, Cai W, Zhu S, Zhu J (2016) 3D self-assembly of aluminium nanoparticles for plasmon-enhanced solar desalination. Nat Photonics 10:393. https://doi.org/10.1038/nphoton.2016.75. https://www.nature.com/articles/nphoton.2016. 75\#supplementary-information

Zhou Z, Peng X, Zhong L, Wu L, Cao X, Sun RC (2016b) Electrospun cellulose acetate supported $\mathrm{Ag} @ \mathrm{AgCl}$ composites with facet-dependent photocatalytic properties on degradation of organic dyes under visible-light irradiation. Carbohydr Polym 136:322-328. https://doi.org/10. 1016/j.carbpol.2015.09.009

Zhu Z, Wu P, Liu G, He X, Qi B, Zeng G, Wang W, Sun Y, Cui F (2017) Ultrahigh adsorption capacity of anionic dyes with sharp selectivity through the cationic charged hybrid nanofibrous membranes. Chem Eng J 313:957-966. https://doi.org/10.1016/j.cej.2016.10.145

Zhu Z, Ma J, Ji C, Liu Y, Wang W, Cui F (2018) Nitrogen doped hierarchically structured porous carbon fibers with an ultrahigh specific surface area for removal of organic dyes. RSC Adv 8 (34):19116-19124. https://doi.org/10.1039/c8ra02512f 